\title{
TRIBALIZACIÓN, JERARQUIZACIÓN Y ESTADO EN EL TERRITORIO DE EL ARGAR
}

\author{
TRIBALISATION, HIERARCHISATION AND STATE IN THE EL ARGAR TERRITORY
}

\author{
por \\ OSWALDO ARTEAGA
}

\begin{abstract}
RESUMEN Desde la perspectiva epistemológica y teórica del materialismo crítico y dialéctico, y desde la estrategia metodológica de una Arqueología Social al servicio de la HISTORIA: exponemos nuestros puntos de vista acerca del proceso que se desarrolla en el Sudeste de la Península lbérica desde el Neolítico Final y la Epoca del Cobre, hasta la Epoca del Bronce. Argumentamos que este proceso histórico comienza con la tribalización segmentaria del territorio (Cultura de Almería), y que pasando por una jerarquización socio-política del mismo (Cultura de Los Millares) acaba en la formación de un Estado centralizado (Cultura de El Argar).
\end{abstract}

ABSTRACT Using the epistemological and theoretical perspective of critical dialectic materialism, and the methodological strategy of social Archaeology, in the service of HISTORY, we expound our points of view about the process developed in the Southeast of the Iberian Peninsula from the Late Neolithic and the Copper Age to the Bronze Age. It is argued here that this historical process starts by the segmentary tribalising of the territory (Culture of Almería), and that, passing through a social-political hierarchization of the territory (Culture of Los Millares), it results in the formation of a centralized State (Culture of El Argar).

\section{INTRODUCCION}

La llamada "Cultura de El Argar" es una de las manifestaciones prehistóricas más relevantes de cuantas se puedan referir a la Epoca del Bronce en el Occidente de Europa. El estudio arqueológico de la misma fue iniciado desde un punto de vista sistemático por los hermanos Enrique y Luis Siret, ingenieros belgas que trabajaron en las explotaciones mineras de la Sierra Almagrera y se afincaron en Cuevas del Almanzora (Almería), donde Don Luis fallecería el día 7 de Junio de 1934; después de una prolongada vida investigadora (Pellicer, 1986). 
La delimitación geográfica de la cultura argárica fue concretada por Miguel Tarradell (1947), que señalaría su expansión por las actuales provincias de Almería y Murcia, abarcando también parte de las de Alicante, Granada y Jaén.

Importantes para la marcha de la investigación durante la década de los años cincuenta fueron, entre otros, los trabajos publicados por E. Cuadrado Díaz (1950) y P. Bosch Gimpera (1954). Pero el umbral de las síntesis modernas fue puesto por B. Blance $(1964 ; 1971)$; siendo su sistematización matizada posteriormente, sobre todo, por H. Schubart $(1975 ; 1976)$, quien acaba de ofrecer una síntesis sobre materiales argáricos, en una obra publicada recientemente (Schubart y Ulreich, 1991).

A partir de mediados de los años setenta nuevos parámetros teóricos se iban a poner en relación con el estudio de la sociedad argárica. En contrastación con análisis tipológicos como los ofrecidos por Schubart, Monteagudo y Ruiz Gálvez (Schubart, 1975; 1976; Monteagudo, 1977; Ruiz Gálvez, 1977), trabajos altamente sugerentes como los de A. Gilman (1976) iban a correr paralelos con la puesta en marcha de las excavaciones sistemáticas en el yacimiento argárico de Fuente Alamo (Cuevas del Almanzora, Almería), que a partir de 1977 se han continuado hasta nuestros días (Arteaga y Schubart, 1980; 1981; Schubart y Arteaga, 1983) obteniéndose importantes resultados estratigráficos (Schubart y Arteaga, 1986), que en su extensión nos han venido permitiendo esclarecer cual era la estructuración habitacional de dicho poblado (Schubart, Arteaga y Pingel, 1985; 1989).

Un nuevo hito de la investigación argárica puede fijarse a partir de 1983, con la publicación de la tesis doctoral de V. Lull. Con una elaborada visión de la sociedad en cuestión, Lull marcaría unas pautas que iban a calar muy hondo, sobre todo desde la perspectiva teórica del materialismo histórico (Lull, 1983). Su aporte es, por lo tanto, junto con el brindado por A. Gilman y J.B. Thornes (1985), un punto de referencia obligado para quienes quieran actualmente introducirse en el campo "teórico" de los estudios argáricos.

En los últimos años, contando con la colaboración de R. W. Chapman, M. Picazo y Mª E. Sanahuja, se han llevado a cabo excavaciones arqueológicas en el poblado argárico de Gatas (Turre, Almería), también por parte de V. Lull, de las cuales conocemos los avances preliminares que se han venido dando a conocer (Chapman et alii, 1985; 1986; 1987).

Una visión renovada, sobre la formación de las sociedades complejas, en el Sureste de la Península Ibérica, en el marco del Mediterráneo Occidental, ha sido explicitada recientemente por Robert Chapman, uno de los más destacados representantes de la arqueología procesual británica: reivindicando en torno a Los Millares y El Argar un desarrollo independiente en la aparición de diferencias de riqueza, status y poder (Chapman, 1990; 1991).

Por nuestra parte, además de las citadas excavaciones de Fuente Alamo, que realizamos en codirección con los colegas Hermanfrid Schubart (Director del Instituto Arqueológico Alemán de Madrid) y Volker Pingel (Catedrático de Prehistoria de la Universidad de Bochum, Alemania), hemos venido llevando a cabo en colaboración con H. Schubart y los geólogos alemanes H.D. Schulz y G. Hoffmann un programa interdisciplinario dedicado a la delimitación de las antiguas líneas costeras en el litoral mediterráneo de Andalucía, que han resultado de una enorme importancia para la reconstrucción paleogeográfica de la Cuenca Terciaria de Vera, incluyendo lo que concierne a los tiempos neolíticos, calcolíticos y argáricos (Arteaga et alii, 1985).

Estos trabajos de campo, los arqueológicos de Fuente Alamo y los geológico-arqueológicos del "Proyecto Costa", son los que nos sirven de base para el planteamiento del "proceso histórico" que concierne a las llamadas culturas de Almería, Los Millares y El Argar, no desde las perspectivas antropológicas de la teoría procesual (Swartz, Turner y Tuden, 1966) que partiendo del "estructural funcionalismo entronca con la Escuela de Manchester (Gluckman, 1956; Turner, 1957; Bailey, 1960) y 
asumiendo a su manera la noción del conflicto social desemboca en la teoría de la acción individualista (Cohen, 1974; 1981) y en la teoría del juego político (Bailey, 1969), sino más bien desde la perspectiva histórica de la teoría de las contradicciones sociales (materialismo histórico) que en las tierras del sudeste de la Península Ibérica desembocan en un proceso de transformaciones relativas no solamente al cambio de la estructura de la sociedad sino paralelamente en la explotación y transformación de su paisaje histórico.

En modo paralelo a las citadas actuaciones geológico-arqueológicas del "Proyecto Costa" y a las excavaciones sistemáticas en Fuente Alamo, también debemos subrayar, por su inminente aporte al conocimiento del mismo yacimiento de El Argar, las prospecciones electro-magnéticas que bajo la dirección de $\mathrm{H}$. Schubart allí se vienen realizando, y que dada la campaña de sondeos arqueológicos realizada durante el otoño de 1991 nos permitirán impulsar el conocimiento de la ordenación del hábitat prehistórico en este asentamiento capital.

\section{Las alternativas teóricas y metodológicas para el estudio de la "Sociedad Argárica" en la actualidad}

Durante los quince años comprendidos entre 1975 y 1990 las nuevas tendencias interpretativas de la Historia y de la Antropología que se venían debatiendo en otros países europeos y americanos comenzaron a introducirse tímidamente en la Península Ibérica, haciendo que muchos de los presupuestos de la metodología arqueológica que aquí se venía aplicando fueran siendo criticados, sobre todo a partir de distintos enfoques entroncados con el funcionalismo, el estructuralismo y el materialismo histórico.

Son varios autores los que desde esas diferentes perspectivas teóricas y metodológicas nos traducen las tendencias investigativas actuales. Con ello se plantea la renovación de un debate, a nuestro entender muy conveniente, para la asunción de un futuro "menos inocente" en la arqueología española (Ruiz Rodríguez et alii, 1986). Nosotros mismos hemos retomado la necesidad de orientar nuestros proyectos investigativos en atención a las alternativas que la arqueología de las últimas cuatro décadas ha venido proponiendo; no habiéndose notado efecto alguno sobre nuestros planteamientos (hablo ahora en lo personal) hasta bien entrada la década de los años setenta. Fue a partir de 1975 aproximadamente, cuando auto-criticando la estrategia positivista e historicista para la cual veníamos trabajando, comenzamos a darnos cuenta de que son las formaciones sociales y no sus manifestaciones culturales, las que traducen en el tiempo y en el espacio los procesos que llamamos históricos (Arteaga, 1980, Tesis Doctoral).

En efecto, podemos añadir al respecto que antes de las investigaciones que ahora nos sirven de apoyo ("Proyecto Fuente Alamo" y "Proyecto Costa") la llamada "Cultura de El Argar" era explicada desde unos planteamientos preferentemente historicistas, evolucionistas y difusionistas, preguntando más por sus orígenes y menos por el proceso histórico al cual era debida. Aunque ya se daban opiniones más centradas en lo social que en lo cultural (Gilman, 1976), desde el punto de vista del historicismo la búsqueda de esos orígenes quedaba expresada mayormente en la comprobación de los "paralelos" encontrados para aquellos "elementos materialmente comparativos", que por sus meras características "tipológicas" eran tomados como fundamentos para la demostración de "relaciones" entre las distintas "áreas".

En esa misma tendencia, el evolucismo culturalista operaba en un sentido marcadamente positivista, al servicio de la clasificación (taxonomía) y datación (ordenación cronológica) de los hallazgos materiales: creando seriaciones de complejos que ayudasen a la definición concreta de dichas áreas $e$ influencias. 
Y para completar la tríada metodológica, el difusionismo se encargaba de constatar el movimiento de pueblos portadores de culturas, sin profundizar realmente en el estudio de los procesos formativos de las sociedades y manifestaciones culturales que aquí se dieron en el pasado.

Las estrategias metodológicas, así decantadas, no eran aplicadas solamente a las investigaciones relativas a las cuestiones argáricas, sino a todas las que se referían a la Prehistoria y a la Protohistoria peninsulares. Los llamados "fenómenos colonizadores" y las oleadas de "invasiones", que nosotros mismos llegamos a poner en tela de juicio (Arteaga, 1977; Arteaga y Molina, 1977; Arteaga, 1978) contaban entonces con no pocos defensores.

No obstante, si bien no faltan prehistoriadores y arqueólogos que todavía reproduzcan las consabidas estrategias de la metodología historicista tradicional, el debate en el campo de la teoría, como hemos dicho, ha dado un giro copernicano, barajándose actualmente en España distintas alternativas interpretativas que hasta no hace mucho, por múltiples motivos igualmente históricos, parecían ser patrimonio de las escuelas extranjeras y un "tabú" en las universidades nuestras.

A partir de reuniones como las celebradas en Soria (1981), Palencia (1985), y Teruel (1984, 1986, 1989) puede decirse que las reflexiones sobre epistemología, teoría, metodología y técnicas aplicadas han ido en aumento, haciéndose cada vez más definidas las posturas críticas que ahora se toman, bien sea en oposición a los historicismos, evolucionismos y difusionismos precedentes, bien sea en la confrontación de todas las tendencias conocidas entre sí. Además de resultar muy constructivo, esto permite que se vayan clarificando algunas incoherencias que todavía se observan, como propias del "impacto" causado por la rápida asimilación de las citadas corrientes; que algunos investigadores han pasado a defender encarecidamente, sin desarrollar en sus propios campos investigativos un trabajo metodológicamente paralelo, que les permita llevarlas a una debida contrastación en el campo de la praxis. Como lo ha expresado V. Lull (1988) se llegan por lo dicho a notar no pocas desconexiones entre las esferas conceptuales y las esferas fácticas.

En los casos más sutiles, tales incoherencias quedan plasmadas en formulaciones eclécticas y en "hibridaciones" conceptuales, conformando explicaciones a base de parámetros teóricos que epistemológicamente son irreconciliables. En los casos más ingenuos, quedan puestas de manifiesto en las aplicaciones técnicas que se realizan, de una manera mecánica, sin analizar los trasfondos teóricos para los cuales sirven. Dicho con otras palabras, todavía se aprecian no pocos desajustes entre los conceptos que se emiten y los trabajos que se presentan para respaldarlos, por lo que la unidad entre la teoría y la práctica no se cumple para que el método investigativo sea realmente coherente.

El estado actual de la cuestión ha quedado cabalmente planteado en los trabajos críticos que, entre otros, han venido publicando autores como A. Ramos Millán (1981), J.M. Vicent (1982), V. Lull (1983; 1988), F. Nocete $(1984 ; 1986 ; 1988)$, C. Martín de Guzmán $(1984 ; 1988)$, F. Criado y otros (1986), A. Ruiz Rodríguez y otros (1986), T. Chapa Brunet (1988), A. Hernando Gonzalo (1988), G. Ruiz Zapatero (1991) y Mª I. Martínez Navarrete (1989).

Hallándonos en cualquier forma delante de una etapa superable y por lo mismo transitoria, no cabe duda de que por el momento se refleja el gran "choque de conceptos" que venimos comentando, como propio de la realidad española de los últimos quince años.

El balance que actualmente creemos que se puede hacer, en razón de todo lo antes dicho, es que nos encontramos en la espiral de un cambio vertiginoso, dentro del cual si bien hemos visto producirse la crisis del historicismo, también se ha observado un cierto movimiento pendular hacia la aceptación prioritaria de otras espectativas metodológicas determinadas más por el funcionalismo y el neopositivismo, que propugnan algunas escuelas, sobre todo británicas y norteamericanas, y menos por las otras corrientes alternativas que igualmente se integran en el debate. 
Esta apertura prioritaria a las corrientes británicas y norteamericanas se ha visto sin duda potenciada por la enorme propaganda que en Europa venía desarrollando la llamada "New Archaeology" (Binford, 1962; 1965; 1972; Clarke, 1968; S. y L. Binford, 1968), la versión arqueológica del neofuncionalismo y del neoevolucionismo en la Ecología Cultural Americana (Gándara, 1982); entroncando con la corriente antropológica de la "Escuela de Manchester" (La Teoría Procesual), como hemos dicho antes.

La "New Archaeology" ha contribuido más que nada a cortarle las alas idealistas al historicismo, pero por el lado neopositivista no ha dejado de fomentar una "atomización" del concepto global de la Historia, con la introducción de esas "varias" arqueologías, adaptativas, sincrónicas, particularistas, que sus defensores proponen. Nos referimos, por su troncalidad con el funcionalismo, a las que más han impactado entre nosotros con los nombres de arqueología espacial (Willey, 1953; 1956; 1966; 1971; Hodder y Orton, 1976; Clarke, 1977; Hietala, 1984; AA.VV. en Burillo, ed., 1984; 1986); arqueología antropológica (Willey y Phillips, 1958; Binford, 1962; Harris, 1968; Sahlins, 1977; Yellen, 1977; Gumerman y Phillips, 1978; Gould y Watson, 1982; Gibbon, 1984; entre otros); arqueología social (Renfrew, 1973a; 1984; Gjessing, 1975; Moberg, 1980; Bintliff, 1984); arqueología económica (Higgs y Vita-Finzi, 1972; Higgs, 1975; Sheridan y Bailey, 1980; Dennell, 1985); arqueología demográfica (Boserup, 1965; Zubrow, 1975; 1976; Hassan, 1974; 1985; Barker, 1984); arqueología de la muerte (Ucko, 1969; Brown, 1971; Chapman, Kinnes y Randsborg, 1981).

No hay que olvidar que por otra parte se vienen promoviendo, como hemos dicho antes, distintas alternativas que se contraponen como derivadas del estructuralismo, en las distintas versiones de la arqueología contextual (Chang, 1967; 1968; Trigger, 1968a-b; Schiffer, 1972; 1976; 1982-84; Renfrew, 1973a; Redman, 1978; Gumerman y Phillips, 1978; Gould y Watson, 1982; Butzer, 1982; Hodder, 1982; 1987; Shanks y Tilley, 1987; Criado, 1988).

A todas estas tendencias hay que sumar también las diversas variantes interpretativas del materialismo marxista (Spriggs, 1984) que son igualmente complejas y difíciles de distinguir, dadas las formas en que los seguidores de aquellos postulados intentan adaptarlos a sus respectivos esquemas conceptuales (Klejn, 1973; 1980; Friedman, 1974; Lumbreras, 1974; 1981; Sanoja y Vargas, 1974; Veloz, 1976; 1985; Bate, 1977; 1978; 1982; Friedman y Rowlands, 1978; Carandini, 1979; Montané, 1980; 1982; Gilman, 1981; Sanoja, 1982; Bianchi-Bandinelli, 1982; Lull, 1983; Leone, 1984; Kristiansen, 1984; Ruiz Rodríguez et alii, 1986; Torelli, 1987; Nocete, 1988).

En razón del estado de las confrontaciones teóricas y metodológicas, que ahora mismo retomamos en la Península Ibérica, tanto en el campo de la Arqueología Prehistórica como en el propio de la Arqueología Clásica, Antigua, Media, Moderna e "Industrial", nos encontramos abocados en una especie de carrera para la "recuperación acelerada del tiempo perdido", que en lo tocante a cuanto hemos venido exponiendo no deja de suponer una remoción de aquellos debates que hasta mediados del siglo XX desarrollaron en Francia Marc Bloch y Lucien Febvre, cuando libraron sus batallas contra el positivismo de los historiadores nacionalistas (Michelet, Ranke, Maucalay...), en defensa de una Historia Total (Bloch, 1949; Febvre, 1953).

Nos interesa remarcar la propuesta de una Historia Global, porque encierra en sí misma la alternativa que nosotros queremos asumir frente a otras estrategias metodológicas que se conforman con la evocación de los meros "hechos fácticos" (bien documentados), y frente a esas otras que los "organizan" en parámetros más "sistematizados", pero que a fin de cuentas eluden descubrir en profundidad las contradicciones y problemas reales que se generan en el seno de toda vida en sociedad.

En consecuencia, desde una postura de compromiso y a la vista del rumbo que toman las distintas tendencias de la investigación en España, nosotros expresamos la necesidad de asumir como alternativa 
los postulados de una metodología arqueológica al servicio de la Historia: como un contrapunto crítico de aquellas arqueologías que la seccionan en diversas parcelas para su estudio, abstrayéndolas de su concepto global. Como si las mismas pudieran "integrarse" dentro de unas "ordenaciones" y "sistemas" que en sí mismos funcionan, y no estuvieran dialécticamente confrontadas en todos los procesos históricos.

En el presente ensayo que brindamos desde la revista SPAL, en la óptica de una Arqueología Social al servicio de la Historia, y desde la aceptación del concepto crítico y dialéctico de la Historia Global, nosotros vamos a retomar los argumentos que para la formación del Estado hemos adelantado en otros dos estudios dedicados a El Argar.

El primero, en colaboración con H. Schubart, con motivo del Homenaje a Luis Siret, bajo el título: Fundamentos arqueológicos para el estudio socio-económico y cultural del área de El Argar (Schubart y Arteaga, 1986).

El segundo, ofrecido como base didáctica para las Jornadas de Campo organizadas por el Grupo Andaluz de Cuaternario (AEQUA), bajo el título: Yacimientos arqueológicos y asentamientos del Sudeste (Cuencas del Almanzora-Antas), 15-17 de Marzo de 1991, El Argar (Almería), en prensa.

$\mathrm{Al}$ volver sobre las cuestiones allí planteadas (Arteaga, 1991) intentaremos resumir la manera en que venimos interpretando la formación de un Estado Centralizado en torno al núcleo de El Argar: en virtud de un largo proceso de tribalización y jerarquización del territorio localizado alrededor de la Cuenca Terciaria de Vera, durante los períodos que comprenden el Neolítico Final y la Epoca del Cobre, referidos a la "Cultura de Almería" (Bosch Gimpera, 1932; 1969) y a la "Cultura de Los Millares" (Siret, 1913; G. y V. Leisner, 1943; Almagro y Arribas, 1963; Arribas et alii. 1979; 1981; 1983).

\section{La transformación de las condiciones del medio "heredado" por los argáricos}

En líneas generales puede afirmarse que a tenor de los cambios que se traducen en la trama geológica de la Tierra, la naturaleza sin contar con el hombre puede transformarse en sí misma.

Durante todo el Pleistoceno, parece que los modos de vida desarrollados por el género humano incidieron relativamente poco en los cambios naturales. Con lo cual, es a partir de las condiciones que se propician desde los comienzos del Holoceno, y con el desarrollo de las tecno-culturas propias de los cazadores-recolectores que retoman y organizan en modos diferentes los "productores" neolíticos, cuando el hombre comienza de muy distintas maneras a coadyuvar la transformación de los ecosistemas que explota. Con el Neolítico ya no se trata de una "apropiación depredadora" de los recursos naturales necesarios para la subsistencia, sino de la aplicación de unos sistemas productivos experimentados en la explotación del medio, por parte de hombres organizados en formaciones sociales concretas. Unas formaciones sociales que además son en sí mismas susceptibles de resultar cambiantes, porque en su organización comportan unas relaciones que no se establecen de una manera unilineal y mecanicista, sino más bien de un modo contradictorio y crítico; en unas circunstancias que pueden hallarse variablemente condicionadas por el legado de otras generaciones precedentes.

Es por lo que las tierras del Sudeste que nos ocupa, hallándose afectadas por un proceso de transformación natural, coadyuvado a su vez por las actividades antrópicas, pudieron ser heredadas en condiciones distintas, tanto en lo físico como en lo social; y por lo que las relaciones establecidas entre el hombre y la naturaleza, durante los tiempos transcurridos entre la "Cultura de Almería" y la "Cultura de El Argar" resultaron allí igualmente cambiantes. 
La transformación del medio, por lo mismo, representa para nosotros una variante potencialmente cambiante, pero no la constante que en sí misma determina el cambio social.

No parecen opinar así otros autores, que en lugar de contemplar una transformación dialéctica en la relación "sociedad-medio", comienzan dando por sentada una inmutable condición climática de sequedad en el Sudeste: para explicar en base a esta constante la causa que determina la estructuración de aquellas formaciones sociales que acaban organizándose como "argáricas".

Lo primero que cabe matizar es que, por razones de método, estos modelos interpretativos aunque parten del común análisis de la ecuación hombre-medio para intentar explicar la formación de la sociedad argárica, acaban distanciándose a la hora de pronunciar sus interpretaciones, dado que se apoyan en postulados teóricos divergentes; como son en su oposición al historicismo los propios del funcionalismo, el estructuralismo y el materialismo histórico.

Las opiniones mayoritarias se inclinan afirmando que durante la Prehistoria las condiciones de aridez en el Sudeste eran parecidas a las actuales (Schüle, 1967; 1980; 1986; Chapman, 1978; Gilman, 1976; Gilman y Thornes, 1985; Mathers, 1984b). Otros investigadores apuntan por el contrario la posibilidad de un clima algo más húmedo, y por lo tanto menos seco que el supuesto por aquellos autores (Ramos Millán, 1981; Lull, 1983). Mientras que nosotros, coincidiendo parcialmente con éstos últimos, pero ateniéndonos a la tendencia cálida del Holoceno, abogamos por unas fluctuaciones cambiantes (Hoffmann, 1988) que coadyuvadas por las acciones antrópicas (histórico-culturales) se traducen en el paisaje de nuestros días; en el paisaje que hemos heredado (Arteaga, 1988; 1991).

Es interesante, para el estado actual de la investigación, retener la manera en que estos modelos teóricos exponen el proceso conducente a la eclosión argárica.

Para R. W. Chapman (1978; 1981a-b), de acuerdo con una estrategia metodológica funcionalista, los sistemas hidraúlicos serían fundamentales en el árido Sudeste para la puesta en marcha de una agricultura floreciente, por parte de los grupos parentales que se enterraban en las tumbas colectivas "tipo Millares" y entre los cuales irían destacándose los liderazgos de unas élites emergentes. En las diferencias de riqueza que denotan los ajuares de algunas tumbas, como también en la distribución espacial de unas y otras, aprecia Chapman el reflejo de la jerarquización que habrá de quedar consolidada en la diferenciación que más tarde muestran los ajuares de las sepulturas argáricas.

Para A. Gilman $(1976 ; 1981)$, desde la perspectiva teórica de un materialismo dialéctico, vuelve a ser el clima seco del Sudeste árido la constante determinante de los sistemas hidraúlicos que se introducen para la puesta en producción de nuevas tierras agrícolas, en un medio naturalmente pobre. Según Gilman, tales comunidades prehistóricas tendrían que haber invertido mucha fuerza de trabajo en aquellos sistemas de irrigación, introduciéndose además cultivos intensivos como la vid y el olivo, que por ser duraderos necesitarían del cuidado de unos protectores constantes. Esa organización de la irrigación, y la consecuente transformación de las relaciones de la propiedad, harían acrecentar las desigualdades sociales y fomentarían la aparición del militarismo, en el cual se apoyaría la élite dominante que se afianzaría en El Argar. La crítica que actualmente se hace a la estrategia metodológica de Gilman es que no deja de caer en un cierto determinismo (Spriggs, 1984) al pasar a formular la manera en que él contempla las relaciones de producción con respecto a las fuerzas productivas.

Cabe añadir que la base argumental de su esquema también se resiente, como pasa con la propuesta de Chapman (1978; 1981a-b), por fundamentarla prioritariamente en la conceptualización de unos sistemas hidraúlicos y de unos rigores climáticos tan secos (Gilman y Thornes, 1985) que no quedan actualmente respaldados en los registros arqueológicos.

Los consabidos problemas climáticos de la aridez fueron otra vez replanteados por C. Mathers (1984b), quien aplicando un modelo materialista sistémico busca atenuarlos en base a la contraposición 
de unos mecanismos sociales. Su teoría convierte a esos mecanismos en amortiguadores de los efectos de la aridez, y a su vez en generadores de los grupos gestores de la producción. Para Mathers éstos constituyen las élites que pasan al control socio-político, potenciándose en el desarrollo de una socioeconomía de prestigio.

De acuerdo con otros planteamientos metodológicos, basados esta vez en un materialismo cultural estructuralista, A. Ramos Millán (1981) contempla la posibilidad de un clima menos árido que el actual, para explicar en razón del crecimiento demográfico y de la expansión de los cultivos de secano las contradicciones territoriales que se generan entre las comunidades que iban a establecer las por este autor llamadas "jefaturas argáricas" (Ramos Millán, 1981).

En su citado estudio sobre las formaciones sociales argáricas V. Lull (1983) plantea su génesis y desarrollo en un Sudeste algo más húmedo, a la luz de un proceso económico-social basado en los parámetros del materialismo histórico; aunque luego concluye afirmando un criterio defensor de las "jefaturas argáricas", como hemos visto en Ramos Millán, en un modo interpretativo similar al utilizado por los antropólogos evolucionistas americanos (Lull, 1983: 456 y 458). En un trabajo posterior, V. Lull revisa este punto de vista, considerando que El Argar es una formación económico-social de Estado (Lull y Estévez, 1986: 451).

Frente a la determinante prevalencia que los primeros autores citados le dan a la irrigación, para explicar la base organizativa de la futura sociedad argárica, los investigadores mencionados a continuación no ven tantas dificultades para la potenciación de unos cultivos múltiples en el Sudeste, alternando las leguminosas y los cereales (Martín Socas, 1978).

No cabe duda de que la existencia de conducciones de agua, en algunos poblados como Los Millares (Almería) y el Cerro de la Virgen (Granada), al ser interpretadas como acequias de regadío (Schüle, 1966; 1967) ha influido notablemente en las consecuencias económico-sociales que de ello se han querido sacar (Gilman, 1976; 1981; Gilman y Thornes, 1985; Chapman, 1978; 1981a-b) al hilo de propuestas hidraúlicas como las del "despotismo oriental" (Wittfogel, 1957) para fundamentar la teoría de la formación del Estado.

Sin embargo, no todos los poblados calcolíticos que se conocen en la Europa Occidental (subboreal y subatlántica) parecen tener "acequias" que confirmen la generalización de tales sistemas, para poder hablar de la aparición de unos "estados hidraúlicos". Tampoco se excluye que las citadas conducciones, como más tarde ocurriría con las "cisternas argáricas" (Schubart, Arteaga y Pingel, 1985), estuvieran principalmente concebidas para garantizar el abastecimiento de "agua potable", en aquellos grandes núcleos de poblamiento, y no para la irrigación de cultivos en los terrenos del "secano".

La distinción entre acueductos y acequias de regadio nos parece básica, porque en uno y otro caso no resultan iguales las interpretaciones socio-económicas que se pueden traducir.

Es numerosa la literatura que se puede rastrear en la historiografía, en relación con las teorías relativas a la formación del Estado (Vilar, 1980; García Cotarelo, 1981). Su cuestionamiento no ha dejado de ser retomado por parte de pensadores de las más opuestas tendencias; por lo que además de las perspectivas entroncadas con el materialismo histórico (Engels, 1891; Marx y Hobsbawm, 1965; Hindess y Hirst, 1979) y el estructuralismo marxista francés (Terray, 1971; 1977; Godelier, 1972; 1974 ; 1981) tampoco faltan los debates en el seno de otras corrientes antropológicas, como son aquellas propugnadas por las escuelas norteamericanas (Service, 1962; 1975; Willey, 1962; Adams, 1966; Fried, 1967; Sahlins, 1968; Sanders y Price, 1968; Carneiro, 1970; Wright, 1977; Flannery, 1972; Redman, 1978) que entre las muchas conocidas pueden ser contrastadas: aunque sólo sea para remarcar que desde el campo de las teorías la formación del primer Estado en las tierras del Sudeste de la Península Ibérica no tiene porque haber repetido de una manera obligada los mismos principios 
observados en el modelo hidraúlico, ni por supuesto unas pautas deterministas extrapoladas de cualquier otro modelo conocido. Incluso, ni siquiera tiene que resultar metodológicamente necesario tener que reformular la hipótesis de Wittfogel, para hacerla más "operativa" (Mitchell, 1973). Pues aquí de lo que se trata, antes de escribir la historia, es de contrastar una teoría y praxis, para definir cuales eran los fundamentos económico-sociales del sistema productivo, sobre los que se basaba el desarrollo socio-político del Estado argárico.

En la Península Ibérica, como hemos expuesto antes, el debate teórico sobre la función antropológica e histórica de la arqueología no ha hecho más que comenzar. Y es por ello por lo que nos parece importante retomar, en primer lugar, la cuestión interactiva entre las comunidades pre-argáricas y el medio del Sudeste, con el objeto de contribuir a definir el "modo" económico-social en base al cual se produce el desarrollo que aquí conduce al Estado.

En atención a los resultados analíticos (antracológicos y faunísticos) que venimos obteniendo en las excavaciones de Fuente Alamo (Schubart y Arteaga, 1978; Schubart, Arteaga y Pingel, 1989) nosotros optamos como han hecho Ramos Millán (1981) y Lull (1983) por aceptar para las épocas del Cobre y comienzos del Bronce en el Sudeste una relativa mayor humedad (Schoch y Schweingruber, 1982; Driesch et alii, 1985; Stika, 1985; Hoffmann, 1988).

De acuerdo con nuestros estudios, en los tiempos argáricos existían todavía especies vegetales propias del bosque mediterráneo; que después hubieron de ir desapareciendo, al igual que la fauna correspondiente, antes de quedar el territorio cubierto en grandes extensiones por la creciente expansión de la vegetación subdesértica.

De una manera complementaria a las excavaciones de Fuente Alamo, las investigaciones realizadas en el "Proyecto Costa" nos han permitido comprobar una progresiva colmatación en las antiguas desembocaduras de los ríos Aguas, Antas y Almanzora, ilustrándonos cuán diferente hubo de ser el "paisaje" argárico, en comparación con el Sudeste que conocemos en nuestros días (Arteaga et alii, 1985; 1988; Hoffmann y Schulz, 1986; Hoffmann, 1988).

En el río Antas, cuya desembocadura se encontraba más próxima a la zona de El Argar, existía una especie de "Mar Menor", que abarcaba los actuales terrenos de "La Espesura" y "El Salar", por detrás del espolón alargado de Garrucha; hallándose entonces una isla en el actual enclave de Puerto Rey (Arteaga et alii, 1985; 1988; Dibbern, 1986; Hoffmann, 1988).

Durante los tiempos protohistóricos y romanos la navegación marítima penetraba hasta el interior de este "Mar Menor", en el cual desaguaba todavía el río Antas. Y no fue hasta la Edad Media y la Edad Moderna cuando la erosión acabó de colmatarlo (Dibbern, 1986; Hoffmann, 1988).

Este proceso de transformación del medio, sin embargo, fue más vertiginoso en la zona del río Almanzora: dada la mayor fuerza de explotación que sufrieron las tierras de su cuenca y las sierras vecinas, no solamente desde el punto de vista del sistema agropecuario desarrollado (como vemos alrededor de El Argar), sino también en razón de las actividades minero-metalúrgicas que aquí se hicieron especialmente intensas tanto en lo concerniente al horizonte de Almizaraque (Epoca del Cobre), como en lo referido al horizonte de Fuente Alamo (Epoca del Bronce), como en lo relativo a los tiempos de Villaricos (Epocas púnica y romana).

Hacia los primeros milenios del Holoceno los actuales terrenos del Bajo Almanzora estaban todavía cubiertos por el mar. Una gran bahía penetraba hasta el mismo "tell" de Almizaraque (Arteaga et alii, 1985; Kracht, 1986; Hoffmann, 1988). Durante el Neolítico Final, por esto mismo, los asentamientos humanos quedaban localizados a partir del reborde marítimo de la bahía, en cerros amesetados relativamente próximos al agua dulce y a las zonas más aptas para la agricultura y la ganadería: como era el caso de los pequeños asentamientos comparables al llamado Cabezo del Pajarraco (Siret, 1906), una 
aldea con claras reminiscencias del Neolítico Medio (Pellicer, 1986). Las actividades promotoras del sistema agropecuario que aquí se desarrollan a partir del Neolítico Final no parecen haberse traducido en unas extensivas transformaciones del paisaje hasta los comienzos del Calcolítico, cuando vemos que la erosión colmatadora del estuario del Almanzora empieza a hacerse perceptible.

Como es lógico, la hipotésis que se impone es que las faenas agrícolas en la cuenca, el pastoreo de ovicápridos en los montes, la roturación de las tierras cerealistas, la deforestación creciente de los bosques y la minería, aquí han incidido acelerando las causas erosivas que hicieron transformar el paisaje "heredado" por los argáricos. Unas causas naturales y antrópicas que si bien se acentuaron con mayor fuerza en el Bajo Almanzora, tampoco iban a dejar de sentirse en torno a los ríos Aguas y Antas (Hoffmann, 1988). Con distinto ritmo, pero con similar progresión, este proceso de colmatación erosiva continuaría desarrollándose en las tres cuencas citadas, a lo largo de la Protohistoria y de los tiempos púnicos y romanos, conociendo unos efectos vertiginosos a partir de la Edad Media.

En efecto, ha sido la erosión causada en los tiempos modernos y contemporáneos la que ha alcanzado unas magnitudes verdaderamente catastróficas, arrasando los vestigios que quedaban de los viejos "paisajes" precedentes: en modo tal que las lluvias torrenciales, las "gotas frías" de nuestros días, arrastran margas terciarias, dado que son ellas las que afloran por doquier, al haber desaparecido la vegetación y los antiguos "suelos" (Arteaga et alii, 1985; 1988; Hoffmann, 1988).

De acuerdo con los resultados del "Proyecto Costa", las condiciones medio-ambientales durante el Segundo Milenio lo que permiten asegurar es que se hallaban comprendidas dentro del marco progresivo de las transformaciones que conducen al estado del Sudeste actual, por lo que sin negar una tendencia climática hacia la aridez hay que considerar que los "suelos" no ofrecían las mismas características que ahora; que la maquia mediterránea cubría grandes espacios; que la escorrentía en los ríos era más regular; que el arbolado en las serranías aún no había desaparecido, y que la pluviosidad tenía otros índices anuales.

La implantación de un sistema agropecuario a partir del Neolítico Final resulta en sí misma probatoria de que sin complicados trabajos hidraúlicos, y aunque después los hubiera, el clima mediterráneo del Sudeste era apropiado para la expansión de los cultivos de leguminosas, y de los cereales en los secanos, como también para el desarrollo del pastoreo de ovicápridos en los llanos y montes vecinos de las sierras. Sabemos que la crianza de bóvidos, suidos y équidos, en los terrenos próximos a las grandes cuencas fluviales, era bastante rentable en los tiempos argáricos (Driesch et alii, 1985), cuando el sistema agropecuario básico había alcanzado sus topes productivos más elevados.

Los restos de la fauna salvaje (Driesch et alii, 1985) también nos corroboran que las formaciones boscosas se conservaban todavía relativamente. En cualquier caso, la progresión de la deforestación hubo de constituir un factor altamente pernicioso para la naturaleza del Sudeste. Desde el Neolítico Final grandes extensiones vegetales llegaron a ser desmontadas en favor de la expansión de los pastos para el ganado, y para la preparación de nuevos suelos agrícolas. Toda la madera necesaria para la combustión, tanto en lo tocante a los usos domésticos, como en lo tocante a los hornos cerámicos y metalúrgicos, tuvo que obtenerse en detrimento de la cobertura vegetal que entonces existía.

Para entender la erosión que observamos acumulada en las zonas bajas de las cuencas fluviales (Hoffmann, 1988), debemos analizar la deforestación y la transformación de la cobertura vegetal de la región en un sentido creciente, para una vez así evaluada, en relación con los cambios climáticos naturales de la región del Sudeste, poder explicitar la magnitud del peso coadyuvante que aquí tuvieron las actividades económicas propias del sistema agrícola-ganadero-minero-metalúrgico, desarrollado antes, durante y después de la eclosión argárica.

Todo lo que pueda argumentarse con respecto a los modos de vida argáricos, en consecuencia, nada tiene que ver con el paisaje actual, ni con las condiciones que ahora ofrecen las tierras del Sudeste. Por 
lo que hay que partir de otras evidencias "paleo-geográficas", tales como son las que se traducen en los efectos erosivos que hemos investigado a la luz de los resultados del "Proyecto Costa" (Arteaga et alii, 1985; 1988; Hoffmann, 1988) y que en definitiva nos muestran que las transformaciones del medio estaban interrelacionadas con las actividades antrópicas, relativas a los cambios operados en el seno de las formaciones económico-sociales que se sucedieron en el mismo territorio: explotándolo de distintos modos consecutivos, a partir del Neolítico Final, durante la Epoca del Cobre, y desde los tiempos argáricos hasta nuestros días.

Es por lo que la memoria histórica del territorio comprende la remanencia de muchos paisajes, hasta definirse el que hemos heredado. El proceso natural y la explotación decantada por el "peso cultural" de las formaciones sociales que aquí se han sucedido se han venido conjugando dialécticamente durante un largo proceso transformador, para hacer del Sudeste de la Península Ibérica uno de los paisajes más degradados de la actual Europa (Arteaga, 1988; 1991).

\section{Poblamiento y cambio cultural}

Una de las mayores pólemicas que se han llegado a suscitar con respecto a la "Cultura de El Argar" ha sido la relacionada con el "origen" del poblamiento considerado como "portador" de la misma.

Por las razones que hemos referido al hablar de los efectos del historicismo y del difusionismo, la ecuación pueblo-cultura ha sido hasta hace poco prevalentemente valorada, en el marco general de las discusiones especializadas; sin que paralelamente se hubiera insistido en su contrastación con otras alternativas interpretativas.

Dos posturas antagónicas fueron las que se decantaron entre los primeros investigadores que se ocuparon del tema, y entre aquellos que posteriormente se hicieron sus continuadores. Una versión fue asumida por los llamados "orientalistas" y "europeístas", que buscaron en lo argárico unas componentes básicamente foráneas. La otra versión fue asumida por los opositores "occidentalistas", que defendieron unas componentes más indigenistas.

Nosotros mismos, hacia mediados de los años setenta, habíamos adoptado la propuesta de una perspectiva evolucionista y autóctona. Sin negar el reconocimiento de evidentes relaciones externas (Schubart, 1973; 1976) llegabamos a la conclusión de que la componente dominante de la formación del poblamiento argárico había sido indígena, entroncándola diacrónicamente con las gentes neolíticas de la "Cultura de Almería" (Arteaga, 1976-78; 1980).

Esta misma había sido la visión que tradicionalmente habían defendido investigadores como $P$. Bosch Gimpera (1932; 1944; 1969), y como G. y V. Leisner (1943), siendo estos dos últimos en tales afirmaciones básicamente no "colonialistas", ni "invasionistas". Pero ésta no fue la tónica más generalizada.

Como hemos dicho antes, dominaron otros criterios interpretativos, que al referirse a la Cultura de El Argar no hicieron otra cosa que reproducir "mutatis mutandi" los mismos esquemas conceptuales que por entonces eran aplicados al llamado "Horizonte colonial" de Los Millares, Vila Nova de San Pedro y Zambujal (Siret, 1906; 1907; Blance, 1961; Almagro y Arribas, 1963; Sangmeister, 1964; Savory, 1968; Kalb, 1975; 1988; A. y W. Schüle, 1976), y a las consabidas "invasiones" transpirenaicas (Arteaga, 1977; 1978), que servían por sí mismas para dar explicación a no pocas lagunas de la investigación protohistórica peninsular (Bosch Gimpera, 1932; 1939; Martínez Santa-Olalla, 1946; Maluquer de Motes, 1945-46; 1958; Almagro Basch, 1952; Pericot García, 1952; Beltrán Martínez, 1960). 
Al hilo de las manifestaciones más prudentes que se comenzaron a proponer (Leisner y Schubart, 1966; Schubart, 1971), como bien lo expresaría a mediados de los años ochenta uno de los excavadores del yacimiento de Los Millares, el profesor A. Arribas: "El desarrollo de la tesis de las colonias y de los horizontes de importación ha tenido lugar cuando ya empezaban a ser conocidas algunas dataciones radiactivas para el Sur peninsular y se habían asentado ya las abundantes series establecidas para la zona atlántica europea". Añadiendo a continuación el citado investigador: "Por una parte el enorme esfuerzo realizado para sentar la tesis colonialista y por otra la posición de prudente espera hasta la obtención de series compactas de dataciones que confirmaran la antigüedad de Occidente han sido las causas (...) por las que se han venido manteniendo las tesis difusionistas, a pesar de la intranquilidad y zozobra que cada nueva datación aportaba a sus postulados básicos" (Arribas, 1986: 159).

Sin duda alguna, ha sido en este sentido C. Renfrew uno de los investigadores que durante las últimas décadas más ha defendido la reacción "occidentalista". Partiendo de los postulados básicos del funcionalismo, al oponerse a las tesis orientalistas, ha invertido sus perspectivas sincrónicas, intentando reconciliar las evidencias arqueológicas con el nuevo esquema comparativo aportado por las dataciones del Carbono-14 (Renfrew, 1973a-b).

Las discusiones cronológicas, así encaminadas, muy pronto pasaron a ser contestadas por parte de los defensores de los estudios funcionalistas y evolutivos: más interesados por los procesos relativos al cambio social, enfocándolos desde un punto de vista autóctono (Chapman, 1978; 1981a-b; Gilman, 1976; 1981).

En la línea de algunos trabajos más recientes (Gilman, 1976; Lull, 1983; Ruiz Rodríguez et alii, 1986; Nocete, 1988) nos encontramos ante la disyuntiva aquí planteada de abordar la distinción entre la "formación del poblamiento argárico" y la "formación social argárica", con el objeto de entender el proceso histórico dentro del cual pensamos que se afirma la "cultura" y se produce el "cambio cultural".

Por nuestra parte, no ya en atención al desarrollo cultural, sino a tenor de la antropología físicoanatómica, hemos comenzado a percatarnos de la troncalidad indígena existente entre las comunidades neolíticas del Sudeste y las argáricas gracias a los estudios que al respecto venían realizando en Granada el profesor M. García Sánchez, y durante los años setenta M. Botella López, quien pudo leer su tesis doctoral abordando el interesante problema de las poblaciones argáricas.

Los planteamientos consignados en la bibliografía de comienzos del siglo fueron quedando superados, demostrándose que existían claras homogeneidades entre los restos humanos del Neolítico y los propios del Bronce (Alcobé et alii, 1978).

La problemática fue retomada también por $\mathrm{M}$. Walker, aplicando análisis epigenéticos y estudios multifactoriales, a cráneos prehistóricos del Sudeste, llegando a la identificación de "micro-poblaciones" dentro de un mismo marco de homogeneidad morfológica (Walker, 1985; 1986).

Más recientemente, gracias a la iniciativa de $\mathrm{H}$. Schubart, contamos con otro estudio ofrecido por M. Kunter, publicado en 1990; en el que basándose en los restos argáricos excavados por L. Siret y depositados en el Museo Real de Arte e Historia de Bruselas (Bélgica) y en el Museo Arqueológico Nacional de Madrid, somete a comparación huesos humanos procedentes de: El Argar, El Oficio, Fuente Vermeja, Gatas, Ifre, Zapata, La Bastida y Lugarico Viejo.

Dada la importancia que tiene este último estudio, por referirse a sepulturas excavadas en muchos de los poblados que nos ocupan, vamos a resumir aquí algunos de los resultados que se refieren a la troncalidad genética del poblamiento argárico. Según ha puesto de manifiesto M. Kunter (1990) en su obra: 
1. El estudio realizado en base a los restos óseos conservados en Bruselas y en Madrid ha sido efectuado sobre una suma de 563 individuos de El Argar, 182 de El Oficio y 42 de otros yacimientos. Es decir, sobre un total de 787 individuos argáricos.

2. Tanto los cráneos masculinos, como los femeninos, muestran una gran homogeneidad morfológica. Lo cual se interpreta como probatorio de que no existen ningunos influjos en la estructura biológica del poblamiento del Bronce, en la zona del Almanzora-Antas, ni en otras del Sudeste, que puedan haber sido propiciados por la intromisión de grupos numéricamente considerables, venidos de muy lejos.

3. Los cráneos argáricos pertenecen al círculo formal de los grupos mediterráneos. De acuerdo con los análisis multivariantes efectuados en comparación con restos óseos neolíticos y sobre cráneos relacionados con el Campaniforme se observa que todos ellos muestran grandes analogías, de modo que con respecto al Sudeste se tiene que aceptar una relación genética; y un origen autóctono del poblamiento de El Argar.

4. Las gentes del Campaniforme en Centroeuropa forman un grupo aparte, aislado de los mediterráneos, por lo que su origen biológico no se puede encontrar en la Península Ibérica. A nuestro entender, esta afirmación resulta fundamental para el planteamiento del fenómeno campaniforme a nivel europeo; y también en el Sudeste, en razón del poblamiento proto-argárico, culturalmente hablando.

Lo más importante que cabe remarcar en razón de todos estos estudios antropológicos es que nos permiten conectar tres conclusiones relativas a la "genética" del poblamiento argárico, en contrastación con el concepto dialéctico de las formaciones sociales:

1. Que el poblamiento, conocido como argárico, era troncalmente el mismo que durante "generaciones" había venido habitando en el territorio murciano-almeriense.

2. Que desde la llamada "Cultura de Almería" no se había alterado el tronco étnico aglutinador de aquellas "gentes", que "tribalizaron" las citadas comarcas del Sudeste: por lo que los únicos grandes cambios que se dieron entre ellas fueron los concernientes a sus transformaciones económico-sociales y socio-políticas, que durante el Neolítico Final, el Calcolítico y el Bronce quedaron reflejadas en unas sucesivas ordenaciones territoriales.

3. Que desde el Neolítico Final hasta la época de El Argar, en la Cuenca Terciaria de Vera, como en los territorios vecinos, estamos ante el desarrollo dialéctico de un mismo proceso histórico. Por lo que las ordenaciones sociopolíticas del territorio no son otra cosa que el reflejo de los cambios operados en la estructura de la organización social: primero plasmada en la "tribalización" de aquellas tierras, después desarrollando en su seno las contradicciones jerarquizantes, y finalmente consolidando el sistema centralista que conocemos como argárico.

No creemos, por lo mismo, que se pueda superar la perspectiva historicista y difusionista del llamado "mundo argárico", criticando las visiones culturalistas de cualquier índole, sin profundizar en el estudio de las relaciones sociales que conformaron las bases organizativas de los poblamientos que conocemos como "argáricos" y "argarizados" (Ruiz Rodríguez et alii, 1986). Las menciones relativas a los mismos siempre han de resultar ambiguas, si no se profundiza en el análisis interno de las formaciones sociales que en aquel proceso dialéctico los fueron definiendo en el tiempo y en el espacio.

Siendo así, creemos que no se trata (por lo menos por nuestra parte) de llevar a cabo un arrinconamiento del llamado empirismo positivista, criticando su estrategia al servicio de la descripción y fechación de objetos, estratos, yacimientos y tumbas, con el fin de la compresión de "áreas" e "influen- 
cias", para luego quedar a niveles neopositivistas, funcionalistas, estructuralistas, etc., conformes con unas meras explicaciones normativistas, contextuales, configurativas o significantes. Lo que nos interesa, para ir al fondo de la cuestión, es penetrar en la complejidad de la estructura social, para poner al descubierto las relaciones esenciales que la establecen, y las contradicciones que la dinamizan.

\section{Las bases agropecuarias del proceso}

Se puede convenir a tenor de las más recientes evidencias aportadas por la arqueología de campo (AA.VV. en Homenaje a L. Siret, 1986) que durante la "Epoca de Los Millares" se afirma en el Sudeste de la Península Ibérica la economía productiva que de una manera global podemos denominar agrícola-ganadera-minero-metalúrgica; bajo la condición de no olvidar que la misma se hallaba previamente fundamentada en la consolidación de un sistema productivo agropecuario. Este era el sistema que tras un proceso de tribalización operado en estos territorios, a partir del Neolítico Final y durante el Cobre Antiguo, se iba a continuar desarrollando hasta los tiempos de El Argar. Como puede comprenderse, aquí utilizamos el término "sistema" en relación con el concepto dialéctico de la organización social de los modos productivos, en su contingencia histórica, y no en el sentido de la "teoría de sistemas" que propugna la "New Archaeology".

De acuerdo con el registro arqueológico existente sabemos que este sistema agropecuario, en tanto que potenciaba una alternativa al modelo hidraúlico, pudo ser iniciado por aquellas comunidades neolíticas que se fueron asentando en las márgenes de los grandes ríos del Sudeste; contando para ello con la fuerza de trabajo y con el nivel técnico de que entonces disponían, en modo no solamente suficiente para la explotación de cultivos en torno a los citados cauces fluviales, sino también en los terrenos del secano; en los cuales fueron introducidos unos cultivos "mediterráneos" del más alto rendimiento productivo.

Fueron los cereales y las leguminosas, por sus cualidades germinativas específicas y por las facilidades que ofrecían para la acumulación y la circulación del producto de sus cosechas, los cultivos fundamentales para el desenvolmiento de aquella economía expansiva, que además de permitir la colonización agraria de aquellas nuevas tierras contaba paralelamente con el apoyo de una ganadería basada en la crianza de bóvidos y suidos, así como también en el pastoreo de ovejas y cabras.

Puede afirmarse, por lo mismo, que la estrategia previsiva de los "silos" para el "grano", junto con la propia de los "corrales" para el "ganado", se habían conjugado muy bien por parte de las comunidades neolíticas y calcolíticas del Sudeste, para conseguir reproducir un modo productivo excedentario.

Visto de esta manera, un sistema agropecuario básico no tiene la misma complejidad que puede introducir un sistema hidraúlico: pero tampoco supone una mera conjunción de técnicas y conocimientos agrícola-ganaderos. Puede constituir también el fundamento de un modo de desarrollo, con proyección social, económica y política. Muchos sistemas hidraúlicos pueden incluso quedar comprendidos gracias al desarrollo de estos sistemas básicos, que en realidad no deben de considerarse menos complejos sino de complejidad dialécticamente diferente. Uno de estos sistemas básicos, por supuesto, era el que se desarrollaba en el Sudeste a partir del Neolítico Final: de acuerdo con una forma concreta de articulación del trabajo, de la acumulación productiva y de la distribución de los bienes. La articulación de un modo de producción.

De acuerdo con las condiciones mediterráneas del medio, puestas en relación con el grado organizativo de aquellas comunidades neolíticas, y con la capacidad tecnológica de las mismas, podemos argumentar que el desarrollo del mencionado sistema agropecuario hubo de correr parejo con un 
creciente proceso de sedentarización, conducente a la plasmación de unos patrones de "tribalización" en las tierras del Sudeste. Es decir, cristalizando en un proceso "colonizador", entendiendo el mismo como una forma de apropiación territorial segmentaria, con aldeas independientes, autosuficientes y sin jerarquización.

La localización de estas aldeas se va conociendo bien en las tierras del Sudeste, a pesar de que sus casas, siendo poco numerosas y construidas con materiales muy perecederos, no se han librado de los efectos demoledores de la erosión y otras actividades antrópicas no menos destructivas.

Las citadas aldeas neolíticas ocupaban cerros próximos a los cauces del agua dulce, tales como son los de Cuartillas, El Garcel, Cabezo del Pajarraco, Tres Cabezos, con lo cual se comprende claramente su estrategia, y se comprueba que cerca de las corrientes de agua existían unas condiciones óptimas para que durante el Neolítico Final y durante el Cobre Antiguo se pudieran implantar unas bases subsistenciales y excedentarias, sobre las cuales desarrollar la potenciación del sistema agropecuario colonizador del secano.

Las técnicas constructivas de estas aldeas del Neolítico Final deben ser subrayadas especialmente. No solamente por resultar características por sus casas circulares, con alzados logrados a base de madera, troncos, ramajes y barro, sino por reflejar unos modos de vida que se hicieron tradicionales en el Sudeste y en otros territorios vecinos, de manera que entroncaron con los modos de vida propios de los antiguos pobladores calcolíticos.

Es por ello por lo que muchos poblados del Cobre Antiguo presentan todavía unas técnicas constructivas similares a las del Neolítico Final antes de que se hubiera propagado la arquitectura de la piedra y el adobe, que se generaliza sobre todo a partir del Cobre de Los Millares.

La arquitectura "tipo Millares", junto con la metalurgia del cobre, en comparación con el Neolítico Final, nos va a ofrecer un importante punto de referencia a la hora de matizar el proceso de jerarquización ocurrido en el seno de estas formaciones sociales: el paso de lo comunitario a lo colectivo.

Sin ignorar la importancia complementaria de la ganadería, creemos que se puede traducir ese proceso en razón de los útiles del trabajo agrícola, que servían para la producción de algunos recursos económicos básicos. En este sentido es preciso remarcar que a partir del Neolítico en adelante puede ser la valoración contrastada de las industrias líticas, con las propias de los complejos tipo "Aljoroque/ El Garcel" (Gossé, 1941; Ramos Muñoz, 1991), la que mejor nos ayude a comprender cuales eran las capacidades productivas que podían desarrollar aquellas poblaciones prehistóricas del Sudeste; contando seguramente con la aplicación de la fuerza animal para algunas actividades, con el objeto de intensificar el resultado del trabajo invertido por los efectivos humanos.

Se sabe que toda sociedad transforma el medio para explotarlo a través de su tecnología. Pero la tecnología, si no se contempla como una mera adaptación extrasomática a la naturaleza (Binford, 1964; 1972), ni como una mera respuesta cultural causada por el entorno ecológico (Harris, 1979), sino más bien en razón del propio desarrollo de unas fuerzas productivas, debe ser definida a tenor de cada formáción social. Pues toda estrategia productiva se encuentra ligada al desarrollo de las fuerzas de producción, y a la estructura de una organización social para la producción (Childe, 1936; 1942; 1951).

En consecuencia, salvo contadas excepciones, no deja de resultar lamentable la poca atención que se le suele prestar a las citadas industrias líticas, en comparación con la desorbitada valoración que se le viene dando a los metales; cuando son aquellas las que mejor nos definen las técnicas aplicadas a la producción de algunos bienes básicos para la subsistencia, y las que mejor nos ofrecen la oportunidad de realizar análisis de contrastación con otros factores importantes para la cuantificación de la coherencia entre las relaciones de producción y las fuerzas productivas (Bate, 1982).

Aparte del desarrollo alcanzado por la ganadería complementaria, nosotros creemos que estos pequeños utensilios de piedra soportan uno de los "secretos" más importantes de la economía agrope- 
cuaria que estamos comentando: porque estaban al servicio de la rentabilidad productiva que esperaban conseguir aquellas comunidades, gracias al trabajo invertido en el sector agrícola.

No en balde, la matización espacio-temporal de las industrias líticas en el Sudeste puede ser contrastada no solamente como un recurso tecnológico, al nivel de los medios productivos concernientes a las tres estructuras económico-sociales observadas en los horizontes sincrónicos que se hallan representados en Aljoroque (Gossé, 1941), Almizaraque (Delibes et alii, 1986) y El Argar (E. y'L. Siret, 1890), sino también a la luz de los cambios que se fueron desarrollando diacrónicamente en los modos productivos de las formaciones sociales respectivas (AA.VV. en Homenaje a L. Siret, 1986).

Desde el planteamiento de este proceso concatenante lo que más nos interesa subrayar es que la implantación de un sistema hidraúlico, para conseguir un regadío extensivo, no tenía por que haber sido necesario para la puesta en marcha del sistema agropecuario del Sudeste. Lo cual no niega que algunos sistemas hidraúlicos puedan convertirse en un nuevo desarrollo de las fuerzas productivas, apoyados en sistemas agrarios básicos: tales como aquellos que se consolidaron en el Neolítico Final.

En definitiva, la tecnología no es otra cosa que un factor inestable que se integra en los medios de producción de los que las sociedades disponen para la consecución de sus modos de vida.

Por otra parte, de cara al Sudeste peninsular, creemos que cabe hacer otras puntualizaciones en relación con el sistema agropecuario; que aunque puede ser considerado como una consecución del Neolítico Final, pensamos que debe ser analizado comparativamente con la agricultura y la ganadería del Neolítico Medio, para llegar a captar su verdadera contingencia. Desde la perspectiva diacrónica, incluso puede decirse que la expansión de los sistemas agropecuarios, como otros que promovieron las comunidades del Neolítico Final y del Calcolítico Inicial, no se puede comprender sin el estudio básico de los conocimientos agrícolas y ganaderos que sobre ciertas especies vegetales y animales desarrollaron las poblaciones semi-sedentarias del Neolítico Antiguo y Medio; en zonas de "naturaleza" potencialmente aptas para ello.

Las distribuciones geográficas que adoptan entre Levante, Murcia y Andalucía (AA.VV. en Homenaje a L. Siret, 1986) las comunidades semi-sedentarias del Neolítico Antiguo y Medio (Pellicer, 1963; 1964; Vicent y Muñoz, 1973; Navarrete, 1976; Arribas y Molina, 1978; Pellicer y Acosta, 1982; Acosta y Pellicer, 1990), pero sobre todo las localizaciones observadas en las tierras llanas por aquellas estaciones que muestran una gran frecuentación de las mismas en comparación con las estaciones localizadas en tierras altas (Muñoz Amilibia, 1986), nos parece que se pueden tomar como bastante definitorias de las zonas donde los sustratos formativos de las poblaciones del Neolítico Final pudieron haber llevado a cabo esos "experimentos" agrícolas y ganaderos. Por lo que los sistemas productivos del Neolítico Final deben ser entendidos como unos nuevos desarrollos de aquellas primeras "reevoluciones" dialécticas del Neolítico Antiguo y Medio, recicladas ahora por las formaciones económico-sociales que fueron "tribalizando" cada vez más ámplios y variados territorios: conocidos por ellas en las tierras bajas, en las cuencas fluviales y lacustres, y en las costas.

Un estudio comparativo a todos los niveles, entre las comunidades del Neolítico Medio y las del Neolítico Final se hace tan necesario para aclarar la "génesis" de esta segunda revolución neolítica como por otra parte se hace fundamental un estudio comparativo entre las comunidades epipaleolíticas y las del Neolítico Antiguo, para poder entender la formación de las sociedades productoras que ahora nos ocupan. Porque es en ese proceso que comienza con la primera revolución neolítica donde creemos que se genera la formación de los grupos tribales y de los modos productivos, que contingentemente podrán verse "reciclados" en otros desarrollos más complejos.

Para nosotros la significación que tiene la matización conceptual del "Neolítico Final" es fundamentalmente socio-económica, porque nos permite a partir del "Neolítico Medio" ir definiendo en los 
territorios de la Península Ibérica sistemas ganaderos, y sistemas agrícolas. Y más que eso, el desarrollo diferencial que se aprecia entre unas poblaciones y otras, de acuerdo con las posibilidades dialécticas de llegar a desarrollar formas articuladas y complementarias entre los distintos modos de producir y de vivir (Sanoja y Vargas, 1974). Es decir, porque nos ayuda a enmarcar en unos modos de vida concretos la organización de las culturas agrícolas (agriculturas) y ganaderas (ganaderías), con las cuales se conforman sistemas mixtos: como el que vemos implantarse en el Sudeste, a partir de que aquí se fueron asentando las formaciones sociales que se vienen refiriendo a la llamada "Cultura de Almería". Si bien la noción de la "Cultura de Almería" debe ser matizada, su valoración como una manifestación desconectada de las versiones culturalistas puede permitirnos el replanteamiento de otras alternativas interesantes. Ya que enfocada desde el punto de vista de un proceso dialéctico y no meramente desde la perspectiva de un evolucionismo lineal, sus formaciones económico-sociales pueden ser contrastadas con el desarrollo de la "Cultura de Los Millares", y a su vez con el de la "Cultura de El Argar". En modo tal, que al hablar de aquellas tres "culturas" nos estamos refiriendo a las contradicciones inherentes a las tres grandes estructuras y transiciones que se verifican en las tierras del Sudeste, dentro de un mismo proceso histórico.

La enseñanza que podemos sacar de este proceso dialéctico del Sudeste no la debemos extrapolar de una manera "lineal", "determinista" y "mecanicista", a otras poblaciones de la Península Ibérica. Sin embargo, creemos que puede y debe ser contrastada con esos otros procesos, que por parte de aquellas también se definieron (Nocete, 1988); para llegar a la captación de una Prehistoria más global. Como es la que a todas ellas incumbe, partiendo siempre de los diversos "modos" organizativos del trabajo productivo, sobre todo agrícola y ganadero; sin olvidar otras parcelas económicas aducibles.

No obstante, hay todavía autores que rechazan la plasmación de esos sistemas agropecuarios en la Península Ibérica durante el Neolítico Final, entroncándolos "económicamente" con el sistema agrícola-ganadero-minero-metalúrgico, propio de la Epoca del Cobre. Olvidando así que las bases productivas de las comunidades calcolíticas conocidas en la Península Ibérica, antes que minero-metalúrgicas, eran agrícolas y ganaderas. Olvidando que difícilmente se puede generar una formación económicosocial partiendo meramente del trabajo minero, prescindiendo de un sistema de trabajo subsistencial, desarrollado a niveles excedentarios.

En el caso concreto del Sudeste, antes de que los minerales de cobre se hubieran sumado al renglón económico de las "riquezas añadidas", y antes de que los objetos metálicos se conviertieran en claros exponentes de los cambios sociales que se fueron generando en el seno de aquellas comunidades, resulta obligado tener en cuenta que fueron los resultados agropecuarios los que permitieron sentar las bases del sistema económico-social, comunitario e igualitario, sobre el cual se iban a desarrollar también las actividades minero-metalúrgicas, y, en suma, las contradicciones del proceso "estamental" que cristalizan durante el "Horizonte de Los Millares".

\section{El proceso hacia la jerarquización estamental}

A la luz de los asentamientos que nos ofrecen fases habitacionales propias del Cobre Antiguo, Pleno y Final (AA.VV., Homenaje a L. Siret, 1986) los cambios más importantes que hemos de observar en el Sudeste van a ser, como hemos apuntado, los referidos a los "modos de vida" calcolíticos que a nivel del territorio implican el desarrollo de un nuevo orden económico-social y sociopolítico.

Continuaba con el Cobre Antiguo, por lo mismo, un largo proceso dentro del cual veremos ponerse de manifiesto, en el seno de aquellas comunidades gentilicias, las desigualdades que a la larga van a 
generar entre sus grupos parentales unas relaciones más "estamentales" que paritarias (Godelier, 1974; 1989).

En modo inherente con este proceso interno hubo de verificarse la redefinición del sistema agropecuario, en el sentido de pasar a comprender un sistema agrícola-ganadero-minero-metalúrgico. Partiendo del sistema agropecuario básico, nos interesa subrayar que los excedentes agrícolas y ganaderos fueron aplicados no solamente para la previsión subsistencial, sino también para la potenciación de otras actividades productivas diversificadoras de los renglones económicos, tales como las minerometalúrgicas. Como, por otra parte, para el mantenimiento de una multiplicación de relaciones intertribales, extra-parentales y extra-comunitarias, conducentes al establecimiento de unos mecanismos de circulación de bienes y materias primas cada vez más complejos (Bate, 1977).

Estos "intercambios" de alcance variable no pueden constituir por sí mismos la causa determinante del cambio operado en la organización de la vida productiva de las sociedades segmentarias, pero lo ponen de manifiesto. Resultan sintomáticos del cambio operado en la estructura económico-social: tanto en las formas de producir, como en las formas de organizarse para la producción, y en las formas de utilizacióin del producto del trabajo social.

Las relaciones marítimas y terrestres, que tanto se discuten por parte de difusionistas y funcionalistas, pueden encontrar otros cauces explicativos, integrándose en la dinámica de los sistemas de intercambio que acabamos de referir, y que se fueron consolidando entre aquellas formaciones económicosociales que habían tribalizado las más diversas regiones de la Península Ibérica, fomentando en ellas procesos calcolíticos, que como el del Sudeste iban a tener una larga proyección espacio-temporal. Es decir, atestiguando los poblados y cementerios calcolíticos, desde el período relativo al Cobre Antiguo, una permanencia sedentaria en ámbitos geográficos matizados por la diversificación potencial de sus recursos naturales, renovables y no renovables. Una vez dada la fijación territorial de estos grupos de filiación unilocal, tenemos el punto de partida para considerar el desarrollo de las actividades intercolectivas, y de las relaciones plurilocales.

En torno a las tierras que nos ocupan, los poblados que ofrecen mayores continuidades estratigráficas van a ser aquellos que comienzan con unas casas parecidas a las del Neolítico Final, construidas con materiales perecederos, que luego quedan suplantadas "in situ", por otros patrones con arquitectura de piedra, tapial y adobe. En este sentido diacrónico, si consideramos que los cambios calcolíticos obedecían al afianzamiento territorial de los grupos segmentarios del Neolítico Final, en el Sudeste, creemos que cobra vigencia la expresión de Bosch Gimpera (1944), de que la "Cultura de Los Millares" era al cenit de la "Cultura de Almería".

En yacimientos como Terrera Ventura (Gusi, 1976; 1986) y Almizaraque (Delibes et alii, 1986), sin que falten otros casos como el del Malagón, en el interior (Arribas et alii, 1978; Torre Peña y Sáez, 1986), conocemos secuencias que pueden servirnos para señalar la sucesión estratigráfica de por lo menos tres grandes horizontes, que después quedan matizados de distinta manera, en virtud de las respectivas deposiciones de cada asentamiento:

a. Uno primero, con fases ilustrativas de esa transición calcolítica inicial, que nos recuerda los modos de vida propios del Neolítico Final.

b. Uno segundo, que comprende en su desarrollo la implantación de los citados patrones de asentamiento con la arquitectura "tipo Millares".

c. Uno tercero, que siendo continuador del anterior es relativo al llamado horizonte con campaniforme, que en el Sudeste conecta con la problemática referida al apagamiento de "Los Millares", y con el período "proto-argárico". 
Esta permanencia observada en vertical, en razón de la segunda y tercera fase de los poblados relativamente más pequeños, parece que se corresponde con el crecimiento en horizontal del núcleo de Los Millares donde sin duda quedaba concentrada la congregación jerarquizante más compleja de todo el territorio.

La ordenación espacial de este poblado pudo conocer hasta tres murallas concéntricas, provistas de bastiones, torres y barbacanas. Unos sistemas defensivos nada ingenuos, que además se hallaban reforzados por la protección exterior de diez grandes fortines, emplazados en los cerros que bordeaban al poblado por sus flancos meridionales y orientales (Arribas et alii, 1979; 1981; 1983).

De acuerdo con sus actuales excavadores, en Los Millares tenemos el núcleo más complejo de todos cuantos ahora se conocen en el ámbito mediterráneo (Arribas et alii, 1979; 1981; 1983) y atlántico (Paço y Sangmeister, 1956; Schubart, 1970; Sangmeister y Schubart, 1977), entrando en la categoría urbanística de una auténtica ciudad prehistórica, si lo comparamos con otras ciudadelas fortificadas de su época (Arribas et alii, 1981).

Esa destacada relevancia del núcleo de Los Millares, acusada no solamente con respecto a los demás poblados repetidores de su mismo patrón de asentamiento (AA.VV., Homenaje a L. Siret, 1986), sino también en comparación con los asentamientos pertenecientes a otras comunidades megalíticas que habitaban en el "hinterland" (G. y V. Leisner, 1943; Arribas et alii, 1981; Molina González, 1983), resulta para nosotros probatoria de que ya durante el Cobre Pleno se había ido consolidando en torno al Sudeste una organización política superior a la que modulaban las anteriores comunidades parentales en el mismo territorio. En cualquier caso, se trataba ya de una reestructuración organizativa territorial, que al parecer quedaba nuclearizada jerárquicamente en Los Millares.

Es preciso esperar que las futuras excavaciones determinen si el poblado fue fundado a partir del Cobre Pleno. Pero incluso en el caso de que Los Millares tuvieran un pequeño núcleo inicial, comenzando en el Cobre Antiguo, cosa no demostrada todavía, nos parece que el crecimiento de su poblamiento no dejaría de resultar sosprendente; siendo probable explicarlo como una aglutinación de "gentes", dependientes de los grupos tribales del territorio, con lo cual estaríamos ante una manifiestación nuclear de enormes consecuencias socio-políticas.

Cabe remarcar, aunque sea de pasada que el proceso de jerarquización observado en relación con los poblados, en tanto que diacrónico, quedaba reflejado en las necrópolis. Sobre todo, en vista de la "igualdad grupal" que todavía mostraban las sepulturas colectivas del IV milenio, con ajuares utilitarios y rituales más equiparados (Gilman, 1976; 1987; Chapman, 1977; 1981b; 1985; 1990; Molina González, 1983) en comparación con el engrandecimiento ceremonial que se aprecia durante el Calcolítico, cuando algunas tumbas permiten llegar a establecer estimaciones cualitativas, no solamente de las "riquezas" selectivas que contienen. Es indudable que la aparición generalizada de las tumbas argáricas, en torno a la Cuenca de Vera, resulta ilustrativa de que aquí la antigua "solidaridad clánica" había pasado antes de la Edad del Bronce por un proceso de diferenciación de los "grupos familiares", y que en razón de los mismos cambios sociales y económicos internos acabaría acusándose en las tumbas individuales, conteniendo ajuares personales de distintas categorías (Lull, 1983; Schubart y Arteaga, 1986; Lull y Estévez, 1986):

Lo que en definitiva podemos deducir al respecto de los poblados y necrópolis de la Edad del Cobre, partiendo de la apuntada diversificación económica del sistema productivo, es que también en el Sudeste de la Península Ibérica durante el Calcolítico se comenzaron a definir diferencias en la forma organizativa de las relaciones sociales de producción; y por lo mismo en el modo de acceso a los bienes de producción y reproducción social. No creemos que haga falta esperar hasta El Argar, para buscar las contradicciones que se debatieron de cara a su formación. Con otras palabras: a lo largo del 
Calcolítico los lazos parentales fueron utilizados en función de la reproducción de un nuevo orden socio-político, dentro del cual las crecientes desigualdades gentilicias pudieron irse modulando; en el seno de una organización colectivista (Godelier, 1974; 1989).

La gran contradicción, como podemos comprender, radicaba en que las bases comunitarias de la estructura socio-económica se habían ido poniendo al servicio de una superestructura socio-política colectivista, plasmada en la creciente jerarquización estamental. O sea, que los intereses antagónicos, cifrados entre las "propiedades colectivas" y las "propiedades familiares" en ciernes, tuvieron en esta situación su caldo de cultivo. Desde un punto de vista diacrónico, pero no lineal, a partir del "Horizonte Pleno" de Los Millares la que se iría consolidando en el Sudeste sería una forma de explotación colectivista, precedesora de la forma de explotación clasista que conocemos como argárica.

La discusión ha de quedar centrada en la explicación que le demos al concepto jerárquico de cara a Los Millares, frente al de "centralización" que venimos admitiendo para El Argar.

\section{El proceso hacia la jerarquización clasista}

Los procesos que marcan la transición hacia las primeras sociedades de clases, en tanto que dialécticos, resultan contingentes: pueden darse, pero también pueden verse "bloqueados". Por otra parte, aquellos que se verifican comportan una pluralidad de formas, que ameritan en cada caso un análisis concreto, para poder llegar a descubrirlos (Godelier, 1972; 1974; Amin, 1974; Bettelheim, 1974; Ruiz Rodríguez, 1978).

Esa contingencia, frente al proceso formativo de una sociedad de clases, es la que primero debemos comenzar subrayando en el Sudeste; a partir del llamado período "proto-argárico". Sobre todo en relación con el núcleo poblacional de Los Millares: donde cabría esperar una plasmación y continuidad de las más antiguas organizaciones aristocráticas del territorio, y sin embargo se quedan "bloqueadas", quizás sumidas en el conservadurismo de los estamentos parentales, que se siguen poniendo de manifiesto en los enterramientos colectivos de la cuenca del Andarax, hasta los comienzos de la Epoca del Bronce (Arteaga, 1976-78); mientras el cambio hacia la sociedad de clases donde se adelanta es en la Cuenca Terciaria de Vera, en torno al núcleo de El Argar (Schubart y Arteaga, 1986).

Lamentablemente, no podemos detenernos aquí en la contrastación de todas las hipótesis que se han planteado sobre la "Cultura de Los Millares" para intentar explicar la transición hacia la propia de El Argar; ni tampoco en la discusión de los "mecanismos" que se han venido proponiendo como fórmulas para comprender la formación del Estado en general (Flannery, 1972) partiendo de presupuestos como los del crecimiento de la población (Boserup, 1965), la guerra (Carneiro, 1970), la irrigación (Wittfogel, 1957), el comercio (Rathje, 1971), la simbiosis entre pueblos (Sanders, 1956; Flannery, 1965), la colaboración y la competencia (Sanders y Price, 1968), el poder integrador de las religiones y de los estilos artísticos (Willey, 1962), etc.

No obstante, en espera de poder argumentar nuestra postura más explícitamente, creemos que a lo largo de estas páginas ha quedado patente la manera en que interpretamos la sociedad argárica como una formación de Estado.

Por las razones que nos llevan a plantear una dependencia entre poblados, con respecto a El Argar (Schubart y Arteaga, 1986) y a reconocer la existencia de segregaciones clasistas a niveles locales y territoriales (Arteaga, 1991), pensamos que para superar las contradicciones inherentes al proceso de jerarquización estamental de la Epoca del Cobre, el nuevo desarrollo de las fuerzas productivas argáricas fue centralizado por un aparato de Estado, que dotado de soberanía, poder y fuerza coercitiva lograría administrar las relaciones productivas que desde comienzos del Segundo Milenio se desarro- 
llaron de una forma complementaria entre los asentamientos comprendidos alrededor de la Cuenca Terciaria de Vera.

Como lo confirman los estudios más recientes, fundamentados en la arqueología alicantina, murciana, granadina, jiennense y almeriense (AA.VV., Homenaje a L. Siret, 1986) después de un período formativo en el Sudeste, los centros estatales argáricos se proyectarían sobre sus primeras fronteras socio-políticas, presionando sobre algunos territorios periféricos y penetrando en otros. En el caso de Andalucía Oriental, prenetrando en las tierras que continuaban habitando las comunidades "calcolíticas" que conocíamos desde la "Epoca de Los Millares". En los casos de Andalucía Occidental, Meseta y Levante, conformando "fronteras" de permeabilidad diversa.

Pero tenemos que concluir. Nuestro propósito no es desarrollar aquí la temática de las formaciones estatales argáricas, sino la de exponer nuestro punto de vista sobre algunas líneas interpretativas concernientes a su formación. Para ello, partiendo del análisis geológico-arqueológico de la transformación del medio, para remarcar cual pudo haber sido el "paisaje" natural y social heredado por los argáricos, hemos contrastado a la luz de la antropología física cual era la troncalidad étnica del poblamiento, en comparación con los cambios operados en el seno de consecutivas formaciones económico-sociales: para subrayar cómo fueron éstas últimas las que le fueron dando a la zona de la Cuenca Terciaria de Vera una fisonomía socio-cultural y un carácter socio-político, igualmente variables.

La principal medida de relación, entre tales formaciones económico-sociales y el medio físico natural, la hemos buscado en la valoración del concepto de la explotación sistemática, basando la misma en la tecno-cultura agrícola-ganadera: con el propósito de acentuar su importancia, y, sin olvidar otros factores que por el momento no hemos desarrollado, hacer resaltar que sin irrigación artificial intensiva un sistema agropecuario básico puede tener proyección social, económica y política; pudiendo ser reciclado de acuerdo con las estructuras organizativas de unos nuevos modos productivos, en función de la potenciación de unos nuevos modos de vida.

De esta manera, pasando a la valoración de la gran expansión económica que llamamos agrícolaganadera-minera-metalúrgica, en estrecha correspondencia con la diversificación colectivista de las formas productivas inherentes a las sociedades calcolíticas, hemos procurado señalar el proceso "contradictorio" y "conflictivo" dado entre la sociedad segmentaria, igualitaria, del Neolítico Final y la sociedad de clases propia de El Argar.

La conclusión a la cual hemos llegado, no como solución resolutoria, sino como hipótesis abierta a la discusión, es que la realidad histórica de El Argar, como propia de un estado de explotación clasista, hubiera sido precedida por un estado de explotación colectivista, concerniente éste último al proceso económico-social desarrollado en el "Horizonte de Los Millares".

La alternativa investigativa que se abre ante nosotros no es otra que la de profundizar en la discusión de los problemas aquí planteados, contribuyendo a su esclarecimiento mediante una metodología aplicada desde la praxis de la arqueología de campo; procurando, a pesar de nuestras propias contradicciones, ser coherentes con los principios epistemológicos y críticos de la corriente teórica que aquí hemos adoptado.

Es decir, intentar "descubrir" el modo en que aquellas comunidades aldeanas del Neolítico Final pudieron llegar a "tribalizar" las tierras del Sudeste, apoyándose principalmente en el cultivo de los cereales y en la crianza de animales domésticos, tales como la cabra, la oveja, el cerdo y el ganado vacuno. Para luego acceder al estudio de la tecnología aplicada, la especialización del trabajo producti- 
vo, la complejidad operativa del sistema agrícola-ganadero-minero-metalúrgico, la organización del comercio: y, sobre todo, cuales fueron en cada circunstancia las relaciones sociales de producción. Para de una manera estrechamente ligada con ellas procurar definir las formas de acumulación, consumo y circulación del producto social del trabajo; no de una forma "sistemática" y "explicativa", sino evaluadora de las condiciones establecidas de cara al acceso a la propiedad de los bienes de producción y reproducción social, para poder plantear en su justa medida la contrastación crítica entre los "productores de bienes materiales" y los "productores de ideas", dentro de un mismo proceso dialéctico que nos permita penetrar en la emergencia de la separación institucional de unos poderes políticos, económicos y religiosos, en el seno de las primeras comunidades urbanas del Sudeste.

En suma, contrastando con respecto a las líneas generales del desarrollo de las llamadas "civilizaciones urbanas", definidas ya por numerosos autores, el propio desenvolvimiento de esa "no pequeña historia" en la cual las formaciones sociales de la "Cultura de Almería", de la "Cultura de Los Millares" y de la "Cultura de El Argar" pudieron ir avanzando en la superación de las contradicciones inherentes a su organización interna y a su relación con la naturaleza, para así forjarse unas formas de vida cada vez más complejas. Al principio, en aldeas, con silos y corrales compartidos por células familiares igualitarias. Después, en poblados fortificados, ilustrativos de los cambios operados en la diversificación económica, en las formas de propiedad de los medios productivos, en la gestación de estamentos sociales y en la ordenación de territorios determinados políticamente por el hombre. Para finalmente, con El Argar, desembocar en un orden de dependencia entre poblados y asentamientos de diversa categoría, gravitando alrededor de un núcleo principal. O sea, conformando una simbiosis recíproca con el asentamiento capital, para poder mantener la cohesión de una estructura más conflictiva, con clases sociales, sometiéndolas a un sistema compuesto por unidades complementarias, bajo una autoridad central: detentadora del poder, el gobierno y la fuerza.

\section{BIBLIOGRAFIA}

ACOSTA, P. y PELLICER, M. (1990): La Cueva de la Dehesilla (Jerez de la Frontera). Jerez (C.S.I.C.).

ADAMS, R. McC. (1966): The Evolution of Urban Society: Early Mesopotamia and Prehispanic Mexico. Chicago (Aldine).

ALCOBE, S. et alii. (1978): “Anthropologische Reste der neolithischen und frühbronzezeitlichen Bevölkerung der Iberischen Halbinsel". H. Schwabedissen (ed.), Die Anfänge des Neolithikums vom Orient bis Nordeuropa. Teil VIII b, Anthropologie, Teil 2, Köln-Wien : 28-43.

ALMAGRO, M. (1952): "La invasión céltica en España”. Historia de España dirigida por R. Menéndez Pidal. I, 2. Madrid.

ALMAGRO, M. y ARRIBAS, A. (1963): El poblado y la necrópolis megalíticos de Los Millares (Santa Fe de Mondújar, Almería). Bibliotheca Praehistorica Hispana 3. Madrid.

AMIN, S. (1974): Sobre el desarrollo desigual de las formaciones sociales. Barcelona (Anagrama).

ARRIBAS, A. (1986): "La Epoca del Cobre en Andalucía Oriental: Perspectivas de la investigación actual". Homenaje a L. Siret (Cuevas del Almanzora, 1984). Sevilla: 159-166.

ARRIBAS, A. y MOLINA, F. (1978): El poblado de Los Castillejos en las Peñas de los Gitanos (Montefrío, Granada). Campaña de excavaciones de 1971. El corte núm. 1. Granada (Universidad)

ARRIBAS, A. et alii. (1978): "El poblado de la Edad del Cobre de "El Malagón" (Cúllar-Baza, Granada). Campaña de 1975". Cuadernos de Prehistoria de la Universidad de Granada 3: 67-116.

(1979): "Excavaciones en Los Millares (Santa Fe, Almería). Campañas de 1978 y 1979". Cuadernos de Prehistoria de la Universidad de Granada 4: 61-109.

(1981): "Excavaciones en Los Millares (Santa Fe de Mondújar, Almería). Campaña de 1981". Cuadernos de Prehistoria de la Universidad de Granada 6: 91-121. 
(1983): "Excavaciones en Los Millares (Santa Fe de Mondújar, Almería). Campañas de 1982 y 1983". Cuadernos de Prehistoria de la Universidad de Granada 8: 123-147.

ARTEAGA, O. (1976-78): "Problemática general de la iberización en Andalucía Oriental y en el Sudeste de la Península". Ampurias 38-40 : 23-60.

(1977): "Problemas de la penetración céltica por el Pirineo Occidental (Ensayo de aproximación)". XIV Congreso Nacional de Arqueología (Vitoria, 1975). Zaragoza. : 549-564.

(1978): "Los Pirineos y el problema de las invasiones indoeuropeas. Aproximación a la valoración de los elementos autóctonos". Els pobles pre-romans del Pirineu. 2 Colloqui Int. d'Arqueologia de Puigcerdà (1976): 13-30.

(1980): La formación del poblamiento ibérico. I-III. Universidad de Granada, Tesis doctoral.

(1988): Die Veränderungen der Uferlinien in ihrer Bedeutung für die archäologischen, besonders phönizischen Niederlassungen an der andalusischen Mittelmeerküste. (en prensa).

(1991): El Argar (Almería): Yacimientos arqueológicos y asentamientos del Sudeste. Jornadas de Campo. Grupo Andaluz de Cuaternario (AEQUA), 15-17 Marzo de 1991.

ARTEAGA, O. y MOLINA, F. (1977): "Anotaciones al problema de las cerámicas excisas peninsulares". XIV Congreso Nacional de Arqueología (Vitoria, 1975). Zaragoza : 565-586.

ARTEAGA, O. y SCHUBART, H. (1980): "Fuente Alamo. Excavaciones de 1977". Noticiario Arqueológico Hispánico $9: 245-289$.

(1981): "Fuente Alamo. Campaña de 1979" Noticiario Arqueológico Hispánico 11 : 7-32.

ARTEAGA, O. et alii (1985): "Investigaciones geológicas y arqueológicas sobre los cambios de la línea costera en el litoral de la Andalucía mediterránea. Informe preliminar (1985)". Anuario Arqueológico de Andalucía 1985 II : 117-122.

(1988): "Geologisch-Archäologische Forschungen zum Verlauf der andalusischen Mittelmeerküste". Forschungen zur Archäologie und Geologie im Raum von Torre del Mar 1983/84. Madrider Beiträge 14. Mainz (Philipp von Zabern) : 107-126.

BAILEY, F.G. (1960): Tribe, Caste and Nation. Manchester. (Manchester University Press). (1969): Stratagems and Spoils. New York. (Schocken Books).

BARKER, G. (1984): Ambiente e societá nella preistoria dell' Italia centrale. Roma (La Nuova Italia Scientifica).

BATE, L.F. (1977): Arqueología y materialismo histórico. México (Ed. de Cultura Popular). (1978): Sociedad, formación económica-social y cultura. México (Ed. de Cultura Popular). (1982): "Hacia la cuantificación de las fuerzas productivas en arqueología". Teorías, métodos y técnicas en arqueología. Instituto Panamericano de Geografía e Historia. México : 51-58.

BELTRAN, A. (1960): "La indoeuropeización del Valle del Ebro". I Symposium de Prehistoria Peninsular. (Pamplona, 1959) : 103-124.

BETTELHEIM, Ch. (1974): La Transición de la Economía Socialista. Barcelona.

BIANCHI-BANDINELLI, R. (1982): Introducción a la Arqueología. Madrid (Akal).

BINFORD, L.R. (1962): "Archaeology as Anthropology". American Antiquity 28 (2) : 217-225.

(1964): "A Consideration of Archaeological Research Design". American Antiquity 29 (4) : 425-441.

(1965): “Archaeological Systematics and the Study of Culture Process". American Antiquity 31 (2) : 203-210. (1972): An Archaeological Perspective. New York-London (Academic Press).

BINFORD, S.R. y L.R. (eds.) (1968): New Perspectives in Archaeology. Chicago (Aldine).

BINTLIFF, J. (ed.) (1984): European Social Evolution: Archaeological Perspectives. Bradford (University).

BLANCE, B. (1961): "Early Bronze Age Colonists in Iberia". Antiquity 35 : 192-202.

(1964): "The Argaric Bronze Age in Iberia". Revista de Guimarâes 74 : 129-142.

(1971): Die Anfänge der Metallurgie auf der Iberischen Halbinsel. Studien zu den Anfängen der Metallurgie 4. Berlin (Gebr. Mann).

BLOCH, M. (1949): Apologie pour l'Histoire ou Métier d'historien. Paris (Armand Colin).

BOSCH GIMPERA, P. (1932): Etnología de la Península Ibérica. Barcelona.

(1939): Two Celtic Waves in Spain. Memorial Lecture. British Academy. London.

(1944): El poblamiento antiguo y la formación de los pueblos de España. México. 
(1954): "La Edad del Bronce de la Península Ibérica". Archivo Español de Arqueología 27 : 45-92.

(1969): "La cultura de Almería". Pyrenae 5 : 47-97.

BOSERUP, E. (1965): The Conditions of Agricultural Growth. Chicago (Aldine).

BROWN, J.A. (ed.) (1971): Approaches to the Social Dimensions of Mortuary Practices. Washington D.C.

BURRILLO. F. (ed.) (1984): Coloquio sobre distribución y relaciones entre los asentamientos. Arqueología Espacial 1-6. Teruel (Colegio Universitario).

(1986): Coloquio sobre el microespacio. Arqueología Espacial 7-10. Teruel (Colegio Universitario).

BUTZER, K.W. (1982): Archaeology as Human Ecology: Methods and Theory for a Contextual Approach. Cambridge (University Press).

CARANDINI, A. (1979): Archeologia e Cultura Materiale. 2.. ed. Bari (De Donato).

CARNEIRO, R.L. (1970): “A Theory of the Origin of the State". Science $169: 733-738$.

CHANG, K.C. (1967): Rethinking Archaeology. New York (Random House).

(1968): Settlement Archaeology. Palo Alto, California. (National Press). (K.C. Chang ed.).

CHAPA, T. (1988): "Perspectivas actuales de la arqueología española". Revista de Occidente 81 : 135-142.

CHAPMAN, R.W. (1977): "Burial Practices: An Area of Mutual Interest". M. Spriggs (ed.) Archaeology and Anthropology: Areas of Mutual Interest. B.A.R. Suppl. Series 19. Oxford : 19-33.

(1978): "The Evidence for Prehistoric Water Control in South-East Spain". Journal of Arid Environments 1 : 261-274.

(1981a): "Los Millares y la cronología relativa de la Edad del Cobre en el Sudeste de España". Cuadernos de Prehistoria de la Universidad de Granada 6 : 75-89.

(1981b): “Archaeological Theory and Communal Burial in Prehistoric Europe" I. Hodder et al. (eds.) Pattern of the Past. Studies in Honour of David Clarke. Cambridge (University Press): 387-411.

(1985): "The Later Prehistory of Western Mediterranean Europe: Recent Advances". Advances in World Archaeology 4. New York (Academic Press) : 115-187.

(1990): Emerging complexity. The Later Prehistory of SouthEast Spain, Iberia and the West Mediterranean. Cambridge. (University Press).

(1991): La Formación de las Sociedades Complejas. El Sureste de la Península Ibérica en el marco del Mediterráneo Occidental. Barcelona. (Crítica).

CHAPMAN, R.W., KINNES, I., RANDSBORG, K. (eds.) (1981): The Archaeology of Death. Cambridge (University Press).

CHAPMAN, R.W. et alii. (1985): "Avance de la prospección arqueológica en el yacimiento de Gatas (Turre, Almería). Septiembre-Octubre, 1985". Anuario Arqueológico de Andalucía 1985 II : 33-41.

(1986): "Informe preliminar de la 2ª campaña del Proyecto Gatas (Turre, Almería)". Anuario Arqueológico de Andalucía 1986 II : 296-301.

(1987): Proyecto Gatas, I: Prospección Arqueológica. B.A.R. International Series 348. Oxford.

CHILDE, V.G. (1936): Man Makes Himself. London (C.A. Watts).

(1942): What Happened in History. Harmondsworth (Penguin Books).

(1951): Social Evolution. London (C.A. Watts).

CLARKE, D.L. (1968): Analytical Archaeology. London (Methuen).

(1977): Spatial Archaeology. London (Academic Press). (D.L. Clarke ed.)

COHEN, A. (1974): Two-Dimensional Man: An Essay on the Anthropology of Power and Symbolism in Complex Societies. London. (Routledge and Kegan Paul).

(1981): The Politics of Elite Culture. Berkeley. (University of California Press).

CRIADO, F. (1988): Contribución al estudio de las relaciones entre las comunidades megalíticas del Noroeste Peninsular y su medio natural: Implicaciones socio-económicas. Universidad de Santiago de Compostela. Tesis Doctoral (inédita).

CRIADO, F. et alii. (1986): La construcción del paisaje megalítico y Ecología en la Sierra de Barbanza. Santiago (Xunta de Galicia).

CUADRADO, E. (1950): "Utiles y armas de El Argar, ensayo de tipología". V Congreso Arqueológico del Sudeste Español. (Almería, 1949), Cartagena. : 103-124. 
DELIBES, G. et alii (1986): "El poblado de Almizaraque”. Homenaje a L. Siret. (Cuevas del Almanzora, 1984). Sevilla. : 167-177.

DENNELL, R. (1985): European Economic Prehistory: A New Approach. London (Academic Press).

DIBBERN, H. (1986): Zur holozänen Küstenlinienentwicklung im Bereich Garrucha (Andalusien, Südostspanien) mit geologischer Kartierung. Universidad de Kiel (Alemania). Tesina de Licenciatura (inédita).

DRIESCH, A. von den et alli. (1985): "Tierknochenfunde aus der bronzezeitlichen Höhensiedlung Fuente Alamo, Provinz Almería". Studien über frühe Tierknochenfunde von der Iberischen Halbinsel 9 : 1-75.

ENGELS, F. (1891): Der Ursprung der Familie, des Privateigenthums und des Staats. 4ª ed., Stuttgart.

FEBVRE, L. (1953): Combats pour l' histoire. Paris (Armand Colin).

FLANNERY, K.V. (1965): "The Ecology of Early Food Production in Mesopotamia". Science 147 (3663): 1247-1256.

(1972): "The Cultural Evolution of Civilizations". Annual Review of Ecology and Systematics 3 : $399-426$.

FRIED, M.H. (1967): The Evolution of Political Society: An Essay in Political Anthropology. New York (Random House).

FRIEDMAN, J. (1974): “Marxism, Structuralism and Vulgar Materialism". Man 9 (3) : 444-469.

FRIEDMAN, J. y ROWLANDS, M.J. (eds.) (1978): The Evolution of Social Systems. London (Duckworth).

GANDARA, M. (1982): “La Vieja 'Nueva Arqueología”", I y 11. Teorías, métodos y técnicas en arqueología. Instituto Panamericano de Geografía e Historia. México : 59-97 y 99-159.

GARCIA COTARELO, R. (ed.) (1981): Introducción a la Teoría de Estado. Barcelona (Teide).

GIBBON, G. (1984): Anthropological Archaeology. New York.

GILMAN, A. (1976): "Bronze Age Dynamics in Southeast Spain”. Dialectical Anthropology 1 : $307-319$.

(1981): "The Development of Social Stratification in Bronze Age Europe". Current Anthropology 22 (1): 1-23:

(1987): "El análisis de clase en la prehistoria del Sudeste". Trabajos de Prehistoria 44 : 27-34.

GILMAN, A. y THORNES, J.B. (1985): Land-use and Prehistory in Southeast Spain. London (Allen \& Unwin).

GJESSING, G. (1975): "Socio-archaeology". Current Anthropology 16 (3) : 323-341.

GLUCKMAN, M. (1956): Custom and Conflict in Africa. New York. (Barnes \& Noble).

GODELIER, M. (1972): Esquemas de evolución de las sociedades. Madrid (Gráficas Xucar). (1974): Economía, Fetichismo y Religión en las sociedades primitivas. Madrid (Siglo XXI). (1981): Instituciones Económicas. Barcelona (Anagrama).

(1989): Lo ideal y lo material. Pensamiento, economías, sociedades. Madrid (Taurus Humanidades).

GOSSE, G. (1941): “Aljoroque, estación neolítica inicial, de la provincia de Almería”. Ampurias 3 : 63-84.

GOULD, R.A. y WATSON, P.J. (1982): “A Dialogue on the Meaning and Use of Analogy in Ethnoarchaeological Reasoning". Journal of Anthropological Archaeology 1 : 355-381.

GUMERMAN, G.J. y PHILLIPS, D.A. (1978): “Archaeology beyond Anthropology". American Antiquity 43 : 184-191.

GUSI JENER, F. (1976): “Resumen de la labor en el yacimiento de Tabernas (Almería)". Noticiario Arqueológico Hispánico-Prehistoria 5 : 199-205.

(1986): "El yacimiento de Terrera Ventura (Tabernas) y su relación con la Cultura de Almería". Homenaje a L. Siret. (Cuevas del Almanzora, 1984). Sevilla : 192-195.

HARRIS, M. (1968): The Rise of Anthropological Theory: A History of Theories of Culture. New York (Crowe11).

(1979): Cultural Materialism: The Struggle for a Science of Culture. New York (Random House).

HASSAN, F.A. (1974): "Population Growth and Cultural Evolution". Rev. Anthropol. 1 : 205-212. (1985): Demographic Archaeology. New York (Academic Press).

HERNANDO GONZALO, A. (1988): Evolución interna y factores ambientales en la interpretación del Calcolitico del Sureste de la Península Ibérica. Una revisión crítica. Colección Tesis Doctorales, 188/88. Universidad Complutense. Madrid.

HIETALA, H. (ed.) (1984): Intrasite Spatial Analysis in Archaeology. Cambridge (University Press). 
HIGGS, E.S. (ed.) (1975): Palaeoeconomy. Cambridge (Univerisity Press).

HIGGS, E.S. y VITA-FINZI, C. (1972): "Prehistoric Economies: A Territorial Approach". E.S. Higgs (ed.). Papers in Economic Prehistory. Cambridge (University Press) : 27-36.

HINDESS, B. y HIRST, P.Q. (1979): Los modos de Producción Precapitalistas. Barcelona (Crítica).

HODDER, I. (1982): Symbols in Action. Cambridge. (University Press).

(1987): The Archaeology of Contextual Meanings. Cambridge. (University Press).

HODDER, I. y ORTON, C. (1976): Spatial Analysis in Archaeology. Cambridge (University Press).

HOFFMANN, G. (1988): Holozänstratigraphie und Küstenlinienverlagerung an der andalusischen Mittelmeerküste. Berichte aus dem Fachbereich Geowissenschaften der Universität Bremen, 2. Bremen.

HOFFMANN G. y SCHULZ, H.D. (1986): "Holocene Stratigraphy and Changing Coastlines in Southern Spain". First International Symposium on Harbours, Port Cities and Coastal Topography. Haifa. Summaries : 87-90.

KALB, Ph. (1975): "Arquitectura de las colonias del Bronce I“. XIII Congreso Nacional de Arqueología (Huelva, 1973). Zaragoza : 383-386.

(1988): "Megalithic Remains and Neolithization in the Iberian Península". Berytus 36 : 53-68.

KLEJN, L.S. (1973): "Marxism, the Systemic Approach, and Archaeology". C. Renfrew (ed.). The Explanation of Culture Change. Models in Prehistory. London. : 691-710.

(1980): "Panorama de l'Archéologie Theorique". A. Schnapp (ed.). L'Archéologie aujourd' hui. Paris.

KRACHT, F. (1986): Holozäne Küstenlinienverlagerung am Unterlauf des Río Almanzora im Tertiärbecken von Vera (Südostspanien). Universidad de Kiel (Alemania). Tesina de Licenciatura (inédita).

KRISTIANSEN, K. (1984): "Ideology and Material Culture: An Archaeological Perspective". M. Spriggs (ed.). Marxist Perspectives in Archaeology. Cambridge : 72-100.

KUNTER, M. (1990): Menschliche Skelettreste aus Siedlungen der El Argar-Kultur. Madrider Beiträge 18. Mainz (Philipp von Zabern).

LEISNER, G. y V. (1943): Die Megalithgräber der Iberischen Halbinsel, I. Der Süden. Römisch-Germanische Forschungen 17. Berlin (Walter de Gruyter).

LEISNER, V. y SCHUBART, H. (1966): "Die Kupferzeitliche Befestigung von Pedra do Ouro/Portugal“". Madrider Mitteilungen 7 : 9-60.

LEONE, M. (1984): "Interpreting Ideology in Historical Archaeology: The William Paca Garden in Annapolis, Maryland". D. Miller y C. Tilley (eds.). Ideology, Power and Prehistory. Cambridge.

LULL, V. (1983): La "Cultura" del Argar. Un modelo para el estudio de las formaciones económico-sociales prehistóricas. Madrid (Akal).

(1988): "Hacia una teoría de la representación en Arqueología". Revista de Occidente 81 : 62-76.

LULL, V. y ESTEVEZ. J. (1986): "Propuesta metodológica para el estudio de las necrópolis argáricas". Homenaje a L. Siret. (Cuevas del Almanzora, 1984) Sevilla : 441-452.

LUMBRERAS, G.L. (1974): La Arqueología como Ciencia Social. Lima (Histar). (1981): Arqueología de la América Andina. Lima (Milla Batres).

MALUQUER DE MOTES, J. (1945-46): "Las culturas hallstátticas en Cataluña" Ampurias 7-8 : $115-184$. (1958): El yacimiento hallstáttico de Cortes de Navarra (Estudio Crítico II). Pamplona.

MARTIN DE GUZMAN, C. (1984): "Nociones epistemológicas y arqueología prehistórica". Primeras Jornadas de Metodología de Investigación Prehistórica. (Soria, 1981). Madrid : 35-64.

(1988): “Arqueología y paradigma: tendencias y resistencias". Revista de Occidente 81 : 27-46.

MARTIN SOCAS, D. (1978): “Aproximación a la economía de la mitad meridional de la Península Ibérica durante el Eneolítico". Zephyrus 28-29 : 163-190.

MARTINEZ NAVARRETE, Mª I. (1989): Una revisión crítica de la prehistoria española: la edad del Bronce como paradigma. Madrid (Siglo XXI).

MARTINEZ SANTA-OLALLA, J. (1946): Esquema paletnológico de la península hispánica. Madrid.

MATHERS, C. (1984a): "Beyond the Grave: The Context and Wider Implications of Mortuory Practices in Southeast Spain”. T.F.C. Blagg et al. (eds.). Papers in Iberian Archaeology. B.A.R. International Series 193, 1. Oxford : 13-46.

(1984b): “'Linear Regression', Inflation and Prestige Competition: 2nd Millennium Transformations in 
South-east Spain". W.H. Waldren et al. (eds.). The Deya Conference of Prehistory. B.A.R. International Series 229, IV. Oxford : 1167-1196.

MARX, K. y HOBSBAWN, E.J. (1965): Pre-capitalist Economic Formations. London (Lawrence \& Wishart).

MITCHELL, W.P. (1973): "The Hidraulic Hypothesis: A Reappraisal". Current Anthropology 14 (5) : 532-534.

MOBERG, C.A. (1980): "Vers une analyse sociologique en archéologie". A. Schnapp (ed.). L'Archéologie aujourd' hui. Paris : 305-316.

MOLINA GONZALEZ, F. (1983): Prehistoria de Granada. Granada (Ed. Don Quijote).

MONTANE, J.C. (1980): Marxismo y Arqueología. México (Ed. de Cultura Popular).

(1982): "Sociedades igualitarias y modo de producción". Teorías, métodos y técnicas en arqueología. Instituto Panamericano de Geografía e Historia. México : 191-209.

MONTEAGUDO, L. (1977): Die Beile auf der lberischen Halbinsel. Prähistorische Bronzefunde, Serie IX. vol. 6. München (C.H. Beck).

MUÑOZ, A.M". (1986): "El Neolítico y los comienzos del Cobre en el Sureste". Homenaje a L. Siret. (Cuevas del Almanzora, 1984). Sevilla : 152-156.

NAVARRETE, M M S. (1976): La Cultura de las Cuevas con cerámica decorada en Andalucía Oriental. I-II. Granada (Universidad).

NOCETE, F. (1984): "Jefaturas y Territorio: una visión crítica". Cuadernos de Prehistoria de la Universidad de Granada $9: 289-304$.

(1986): "Una Historia Agraria: EL proceso de consolidación de la economía de producción (Perspectivas en la investigación del Cobre y Bronce en el Alto Guadalquivir)". A. Ruiz Rodríguez et alii. Arqueología en Jaén (Reflexiones desde un proyecto arqueológico no inocente). Jaén : 91-99.

(1988): 3000-1500 B.C.: La formación del Estado en las campiñas del Alto Guadalquivir. Análisis de un proceso de transición. Universidad de Granada. Tesis Doctoral.

PAÇO, A. do y SANGMEISTER, E. (1956): "Vila Nova de S. Pedro, eine befestigte Siedlung der Kupferzeit in Portugal". Germania $34: 211-230$.

PELLICER, M. (1963): Estratigrafía prehistórica de la Cueva de Nerja (Málaga). Excavaciones Arqueológicas en España 16. Madrid.

(1964): El Neolítico y el Bronce de la Cueva de la Carigüela de Piñar (Granada). Trabajos de Prehistoria XV. Madrid.

(1986): "Perfil biográfico de Luis Siret". Homenaje a L. Siret. (Cuevas del Almanzora, 1984). Sevilla : 13-18.

PELLICER, M. y ACOSTA, P. (1982): "El Neolítico Antiguo en Andalucía Occidental". Le Néolithique Ancien Méditerranéen. Actes du Colloque Int. de Prehistoire. (Montpellier, 1981) : 49-60.

PERICOT, L. (1952): Las raíces de España. Madrid (C.S.I.C.).

RAMOS MILLAN, A. (1981): "Interpretaciones secuenciales y culturales de la Edad del Cobre en la zona meridional de la Península Ibérica. La alternativa del materialismo cultural". Cuadernos de Prehistoria de la Universidad de Granada 6 : 203-256.

(1982): "Hacia un enfoque sintético en el estudio de los artefactos líticos tallados". Cuadernos de Prehistoria de la Universidad de Granada 7 : 405-422.

(1986): "La explotación de recursos líticos por las comunidades prehistóricas. Un estudio sobre economía primitiva". Cuadernos de Prehistoria de la Universidad de Granada 11 : 237-271.

RAMOS MUÑOZ, J. (1991): "Las industrias líticas del Neolítico en Andalucía. Sus implicaciones espaciales y económicas". Zephyrus (en prensa).

RATHJE, W.L. (1971): "The Origin and Development of Lowland Classic Maya Civilization". American Antiquity $36(3): 275-285$.

REDMAN, Ch.L. (1978): The Rise of Civilization: From Early Farmers to Society in the Ancient Near East. San Francisco (W.H. Freeman).

RENFREW, C. (1973a): The Explanation of Culture Change: Models in Prehistory. London (Duckworth). (C. Renfrew ed.).

(1973b): Before Civilization: The Radiocarbon Revolution and Prehistoric Europe. London (Jonathan Cape). 
(1984): Approaches to Social Archaeology. Edinburgh (University Press).

RUIZ-GALVEZ, Ma.L. (1977): "Nueva aportación al conocimiento de la cultura de El Argar". Trabajos de Prehistoria $34: 85-107$.

RUIZ RODRIGUEZ, A. (1978): "Elementos para un análisis de la fase asiática de transición". Primeras sociedades de clase y Modo de Producción Asiático. Madrid (Akal) : 9-41.

RUIZ RODRIGUEZ, A. et alii. (1986): Arqueología en Jaén (Reflexiones desde un proyecto arqueológico no inocente). Jaén (Diputación Provincial).

RUIZ ZAPATERO, G. (1991): "Teoría y metodología en Arqueología”. XX Congreso Nacional de Arqueología. (Santander, 1989). Zaragoza.

SAHLINS, M.D. (1968): Tribesmen. Englewood Cliffs, N.J. (Prentice-Hall).

(1977): Economía de la Edad de Piedra. Madrid (Akal).

SANDERS, W.T. (1956): "The Central Mexican Symbiotic Region: A Study in Prehistoric Settlement Patterns". G.R. Willey (ed.). Prehistoric Settlement Patterns in the New World. New York.

SANDERS, W.T. y PRICE, B.J. (1968): Mesoamerica: The Evolution of a Civilization. New York. (Random House).

SANGMEISTER, E. (1964): "Die Bronzezeit im Westmittelmeer". Saeculum-Weltgeschichte.

SANGMEISTER, E. y SCHUBART, H. (1977): "Zambujal, eine befestigte Siedlung der Kupferzeit in Portugal". Antike Welt $8(3): 23-34$.

SANOJA, M. (1982): "Modos de producción precapitalistas en Venezuela". Teorías, métodos y técnicas en Arqueología. Instituto Panamericano de Geografía e Historia. México : 219-230.

SANOJA, M. y VARGAS, I. (1974): Antiguas formaciones y modos de producción venezolanos. Caracas (Monte Avila Ed.).

SAVORY, H. (1968): Spain and Portugal: The Prehistory of the Iberian Peninsula. London (Thames \& HudSon).

SCHIFFER, M.B. (1972): “Archaeological Context and Systemic Context”. American Antiquity 37 : 156-165. (1976): Behavioral Archeology. London (Academic Press).

(1982-84): Advances in Archaelogical Method and Theory. Selections for Students. New York-London (Academic Pess). (M.B. Schiffer ed.).

SCHOCH, W. y SCHWEINGRUBER, Fr.-H. (1982): "Holzkohlenanalytische Ergebnisse aus der bronzezeitlichen Siedlung Fuente Alamo, Provinz Almería, Spanien”. Archäologisches Korrespondenzblatt 12 : 451-455.

SCHUBART, H. (1970): "Die Kupferzeitliche Befestigung von Columbeira/Portugal". Madrider Mitteilungen 11: 59-73.

(1971): "O Horizonte de Ferradeira. Sepulturas do Eneolítico Final no Sudoeste da Península Ibérica". Revista de Guimarâes 81 (3-4) : 189-214.

(1973): “Mediterrane Beziehungen der El Argar-Kultur". Madrider Mitteilungen 14 : 41-59.

(1975): "Cronología relativa de la cerámica sepulcral en la Cultura de El Argar". Trabajos de Prehistoria 32 : 79-92.

(1976): “Relaciones Mediterráneas de la Cultura de El Argar”. Zephyrus 26-27 : 331-342.

SCHUBART, H. y ARTEAGA, O. (1978): "Fuente Alamo. Vorbericht über die Grabung 1977 in der bronzezeitlichen Höhensiedlung". Madrider Mitteilungen $19: 23-51$.

(1983): “La Cultura de 'El Argar' y las excavaciones en Fuente Alamo (Almería)”, I-III. Revista de Arqueología 24 : 16-27 (parte I); $25: 54-63$ (parte II); $26: 56-63$ (parte III):

(1986): "Fundamentos arqueológicos para el estudio socio-económico y cultural del área de El Argar". Homenaje a L. Siret. (Cuevas del Almanzora, 1984). Sevilla : 289-307.

SCHUBART, H.; ARTEAGA, O. y PINGEL, V. (1985): "Fuente Alamo. Informe preliminar sobre la excavación de 1985 en el poblado de la Edad del Bronce". Ampurias 47 : 70-107.

(1989): "Fuente Alamo. Vorbericht über die Grabung 1988 in der bronzezeitlichen Höhensiedlung". Madrider Mitteilungen $30: 76-91$.

SCHUBART, H. y ULREICH, H. (1991): Die Funde der Südostspanischen Bronzezeit aus der Sammlung Siret. Madrider Beiträge 17. Mainz (Philipp von Zabern). 
SCHÜLE, A. y W. (1976): "Kolonialismus in Europa vor Christi Geburt". Antike Welt 7 (2) : 38-48.

SCHÜLE, W. (1966): "El poblado del Bronce Antiguo en el Cerro de la Virgen de Orce (Granada) y su acequia de regadí". IX Congreso Nacional de Arqueología (Valladolid, 1965). Zaragoza : 113-121.

(1967): "Feldbewässerung in Alt-Europa". Madrider Mitteilungen 8 : 79-99.

(1980): Orce und Galera. Zwei Siedlungen aus dem 3. bis 1. Jahrtausend v. Chr. im Südosten der Iberischen Halbinsel, I: Übersicht über die Ausgrabungen 1962-1970. Mainz (Philipp von Zabern).

(1986): "El Cerro de la Virgen de la Cabeza, Orce (Granada): Consideraciones sobre su marco ecológico y cultural". Homenaje a L. Siret (Cuevas del Almanzora, 1984). Sevilla: 208-220.

SERVICE, E.R. (1962): Primitive Social Organization: An Evolutionary Perspective. New York (Random House).

(1975): Origins of the State and Civilization. The Process of Cultural Evolution. New York (W.W. Norton).

SHANKS, M. y TILLEY, C. (1987): Reconstructing Archaeology. Cambridge (University Press).

SHERIDAN, A. y BAILEY, G. (eds.) (1980): Economic Archaeology. B.A.R. International Series 96. Oxford.

SIRET, E. y L. (1890): Las primeras edades del metal en el Sudeste de España. Barcelona.

SIRET, L. (1906): Villaricos y Herrerías. Antigüedades púnicas, romanas, visigóticas y árabes. Madrid.

(1907): "Orientaux et occidentaux en Espagne aux temps préhistoriques". Revue des Questions Scientifiques. Bruselas.

(1913): Questions de Chronologie et d'Etnographie lbériques, I: De la fin du Quaternaire á la fin du Bronze. Paris.

SPRIGGS, M. (ed.) (1984): Marxist Perspectives in Archaeology. Cambridge (University Press).

STIKA, H.P. (1988): "Botanische Untersuchungen in der bronzezeitlichen Höhensiedlung Fuente Alamo". Madrider Mitteilungen $29: 21-76$.

SWARTZ, M., TURNER, V., TUDEN, A. (eds.) (1966): Political Anthropology. Chicago. (Aldine).

TARRADELL, M. (1947): "Sobre la delimitación geográfica de la cultura del Argar". II Congreso Arqueológico del Sudeste Español. (Albacete, 1946). Cartagena : 139-145.

TERRAY, E. (1971): El Marxismo ante la Sociedad Primitiva. Buenos Aires (Losada).

(1977): "Clases y conciencia de clase en el reino abron de Gyaman". M. Bloch (ed.). Análisis marxistas y Antropología Social. Barcelona (Anagrama) : 105-163.

TORELLI, M. (1987): La societá etrusca. L'etá arcaica, l'éta classica. Roma (La Nuova Italia Scientifica).

TORRE, F. de la y SAEZ, L. (1986): "Nuevas excavaciones en el yacimiento de la Edad del Cobre de "El Malagón' (Cúllar-Baza, Granada)”. Homenaje a L. Siret. (Cuevas del Almanzora, 1984) Sevilla : 221-226.

TRIGGER, B.G. (1986a): Beyond History: The Methods of Prehistory. New York (Holt, Rinehart \& Winston).

(1986b): "The Determinants of Settlement Patterns". K.C. Chang (ed.). Settlement Archaeology. Palo Alto : 5378.

TURNER, V. (1957): Schism and Continuity in an African Society. Manchester. (Manchester University Press).

UCKO, P.J. (1969): "Ethnography and Archaeological Interpretation of Funerary Remains". World Archaeology $1: 262-280$.

VELOZ MAGGIOLO, M. (1976): Medio Ambiente y adaptación humana en la Prehistoria de Santo Domingo. Santo Domingo (Universidad).

(1985): La arqueología de la vida cotidiana. Biblioteca Taller 181. Santo Domingo.

VICENT, A.Mำ y MUÑOZ, A.M‥ (1973): Segunda campaña de excavaciones. La cueva de los Murciélagos, Zuheros (Córdoba), 1969. Excavaciones Arqueológicas en España 77. Madrid.

VICENT, J.M. (1982): “Las tendencias metodológicas en Prehistoria”. Trabajos de Prehistoria 39 : 9-53.

VILAR, P. (1980): Iniciación al vocabulario del análisis histórico. Barcelona (Crítica).

WALKER, M.J. (1985): Characterizing local southeastern Spanish populations of 3000-1500 B.C. B.A.R. International Series 263. Oxford.

(1986): “Avance al estudio de la cranelogía de El Argar y otros yacimientos en el Sureste español". Homenaje $a$ L. Siret. (Cuevas del Almanzora, 1984) Sevilla : 453-466.

WILLEY, G.R. (1953): Prehistoric Settlement Patterns in the Viru Valley, Perú. Washington D.C. 
(1956): Prehistoric Settlement Patterns in the New World. New York (G.R. Willey ed.).

(1962): "The Early Great Styles and the Rise of the Ore-Columbian Civilizations". American Anthropologist $64: 1-14$.

(1966): An Introduction to American Archaeology, I: North and Middle America. Englewood Cliffs, N.J. (Prentice-Hall).

(1971): An Introduction to American Archaeology, II: South America. Englewood Cliffs, N.J. (Prentice-Hall).

WILLEY, G.R. y PHILLIPS, P. (1958): Method and Theory in American Archaeology. Chicago (University Press).

WITTFOGEL, K.A. (1957): Oriental Despotism: A Comparative Study of Total Power. New Haven (Yale University Press).

WRIGHT, H.T. (1977): "Recent Research on the Origin of the State". Annual Review of Anthropology 6 : 379 398.

YELLEN, J.E. (1977): Archaeological Approaches to the Present. London-New York.

ZUBROW, E.B.W. (1975): Prehistoric Carrying Capacity: A Model. Cummings Archaeological Series. Menlo Park. California.

(1976): Demographic Anthropology: Quantitative Approaches. Albuquerque. (E.B.W. Zubrow ed.) 